\title{
Acid resistance system CadBA is implicated in acid tolerance and biofilm formation and is identified as a new virulence factor of Edwardsiella tarda
}

\author{
Chunmei Du ${ }^{1,2,4}$, Xiaoping Huo ${ }^{2,4}$, Hanjie Gu ${ }^{2,6}$, Dongmei $\mathrm{Wu}^{1,5^{*}}$ and Yonghua $\mathrm{Hu}^{2,3,4,6^{*}}$ (])
}

\begin{abstract}
Edwardsiella tarda is a facultative intracellular pathogen in humans and animals. The Gram-negative bacterium is widely considered a potentially important bacterial pathogen. Adaptation to acid stress is important for the transmission of intestinal microbes, so the acid-resistance (AR) system is essential. However, the AR systems of $E$. tarda are totally unknown. In this study, a lysine-dependent acid resistance (LDAR) system in E. tarda, CadBA, was characterized and identified. CadB is a membrane protein and shares high homology with the lysine/cadaverine antiporter. CadA contains a PLP-binding core domain and a pyridoxal phosphate-binding motif. It shares high homology with lysine decarboxylase. $c a d B$ and $c a d A$ are co-transcribed under one operon. To study the function of the cadBA operon, isogenic $c a d A, c a d B$ and $c a d B A$ deletion mutant strains TX01 $\triangle c a d A, T X 01 \triangle c a d B$ and TX01 $\triangle c a d B A$ were constructed. When cultured under normal conditions, the wild type strain and three mutants exhibited the same growth performance. However, when cultured under acid conditions, the growth of three mutants, especially TX01 $\triangle$ cadA, were obviously retarded, compared to the wild strain TX01, which indicates the important involvement of the cadBA operon in acid resistance. The deletion of cadB or cadA, especially cadBA, significantly attenuated bacterial activity of lysine decarboxylase, suggesting the vital participation of cadBA operon in lysine metabolism, which is closely related to acid resistance. The mutations of cadBA operon enhanced bacterial biofilm formation, especially under acid conditions. The deletions of the cadBA operon reduced bacterial adhesion and invasion to Hela cells. Consistently, the deficiency of cadBA operon abated bacterial survival and replication in macrophages, and decreased bacterial dissemination in fish tissues. Our results also show that the expression of cadBA operon and regulator cadC were up-regulated upon acid stress, and CadC rigorously regulated the expression of cadBA operon, especially under acid conditions. These findings demonstrate that the AR CadBA system was a requisite for the resistance of $E$. tarda against acid stress, and played a critical role in bacterial infection of host cells and in host tissues. This is the first study about the acid resistance system of $E$. tarda and provides new insights into the acid-resistance mechanism and pathogenesis of E. tarda.
\end{abstract}

Keywords: Edwardsiella tarda, acid resistance, cadBA, biofilm, pathogenicity, regulation

\footnotetext{
*Correspondence: dmwu@jmsu.edu.cn; huyonghua@itbb.org.cn

${ }^{1}$ College of Basic Medicine, Jiamusi University, 154007 Jiamusi, China

${ }^{2}$ Institute of Tropical Bioscience and Biotechnology, Hainan Academy of Tropical Agricultural Resource, CATAS, 571101 Haikou, China

Full list of author information is available at the end of the article
}

\section{Introduction}

Edwardsiella was isolated from infected humans and animals and identified as a new genus of Enterobacteriaceae in 1965 [1]. Recently, the Edwardsiella genus was classified into five species, including E. tarda, E. anguillarum,

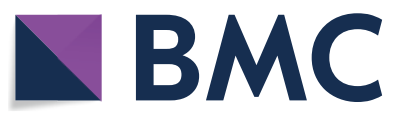

(c) The Author(s) 2021. Open Access This article is licensed under a Creative Commons Attribution 4.0 International License, which permits use, sharing, adaptation, distribution and reproduction in any medium or format, as long as you give appropriate credit to the original author(s) and the source, provide a link to the Creative Commons licence, and indicate if changes were made. The images or other third party material in this article are included in the article's Creative Commons licence, unless indicated otherwise in a credit line to the material. If material is not included in the article's Creative Commons licence and your intended use is not permitted by statutory regulation or exceeds the permitted use, you will need to obtain permission directly from the copyright holder. To view a copy of this licence, visit http://creativecommons.org/licenses/by/4.0/. The Creative Commons Public Domain Dedication waiver (http://creativeco mmons.org/publicdomain/zero/1.0/) applies to the data made available in this article, unless otherwise stated in a credit line to the data. 
E. ictaluri, E. hoshinae, and E. piscicida [2, 3]. E. tarda (now is also considered to be E. piscicida), a member of the family Enterobacteriaceae, is a gram-negative, motile, facultative anaerobe and rod-shaped bacterium $[4,5] . E$. tarda has broad host ranges including aquatic animals, reptiles, amphibians, birds, mammals and humans [6-8], therefore being a significant zoonotic pathogen [9]. This pathogen can cause serious systemic infections and high mortality in both seawater and freshwater fish, accounting for severe economic losses and heavily influencing the healthy development of aquaculture $[10,11]$. Meanwhile, E. tarda is also a fatal gastro-/extraintestinal pathogen in humans. The most frequent manifestation of gastrointestinal infection is a Salmonella-like gastroenteritis. The extraintestinal manifestations of $E$. tarda infection include meningitis, cholecystitis, endocarditis, peritonitis, bacteraemia, septicemia, empyema, liver abscess, intra-abdominal abscess, tubo-ovarian abscess, and skin and soft tissue infection [12, 13], which can eventually lead to severe, systemic, and life-threatening infections. Consequently, E. tarda is widely considered a potentially important bacterial pathogen.

Like other enteric pathogens within the same family such as Escherichia coli, Shigella, and Salmonella species, E. tarda possesses a lot of virulence systems including type III and type VI secretion systems, quorum sensing, two-component systems, and exoenzymes to gain entry into and to survive within the host [3]. Before causing diseases in hosts, pathogenic bacteria often encounter varying environmental stresses including temperature, osmolarity, oxidative stress, $\mathrm{pH}$ fluctuation, famine and so on. Among these environmental stresses, $\mathrm{pH}$ shifts are the most frequent dilemma for pathogens $[14,15]$. These acidic environments include acid soil and fermented food, the harsh inorganic and organic volatile fatty environment in the gastrointestinal tract, as well as mild to moderate acids in phagosomes of cell macrophages [16]. Therefore, an important strategy for pathogens is to adapt to the acidic stress environment of the host. To counter intracellular and extracellular acid stresses, bacteria have developed passive and active protective mechanisms [17]. Among these mechanisms, the amino acid-dependent acid resistance (AR) system is composed of a cytoplasmic decarboxylase that catalyzes a proton-dependent decarboxylation of a substrate amino acid, and an inner membrane substrate/product antiporter that exchanges external substrate for internal product [18]. In E. coli, the AR systems that have been identified are the glutamic acid-dependent acid resistance (GDAR) system [19], the arginine-dependent acid resistance (ADAR) system [20], the lysine-dependent acid resistance (LDAR) system [21] and the ornithine-dependent acid resistance (ODAR) system [22]. Each of these systems has a different optimum
$\mathrm{pH}$ and is capable of providing protection against acid stress over a broad range of $\mathrm{pH}$ values [23].

The LDAR system is a mild acid tolerance response system. In E. coli, the LDAR system consists of the cytoplasmic protein CadA, the integral membrane proteins $\mathrm{CadB}$, and one-component regulator $\mathrm{CadC}$ [24]. CadA, the inducible lysine decarboxylase, is encoded by $\operatorname{cadA}$ gene that converts lysine to cadaverine with consumption of a proton $[25,26]$. CadB, the lysine/cadaverine antiporter with 12 transmembrane helices, is encoded by the $\operatorname{cadB}$ gene that transports lysine into the cell and exports cadaverine. $c a d B$ and $c a d A$ are organized in one operon which work together to maintain $\mathrm{pH}$ homeostasis inside the cell and extracellular environment [27]. CadC is a membrane-integrated transcription activator located upstream of $c a d B$. The regulator belongs to the ToxR family, consisting of a cytoplasmic N-terminal DNAbinding domain that regulates transcription, a transmembrane helix, and a C-terminal periplasmic sensory domain [28]. Under conditions of acidic pH and exogenous lysine, CadC interaction with the lysine-specific permease LysP senses signal transduction to the DNAbinding domain via the transmembrane helix [29]. DNAbinding domain undergoes structural changes that enable the winged protein to interact with the target promoter of cadBA and activated expression of the cadBA operon [30]. The LDAR system has been thoroughly studied in Enterobacteria such as E. coli [31], Salmonella typhimurium [15] and Vibrio [32] because of direct links between the efficiency of the acid stress response and pathogenicity, but little is known about biological roles in E. tarda.

In this study, we investigated the properties of $c a d B A$ operon in $E$. tarda, and analyzed its distinct roles in the physiological fitness and pathogenesis in in vitro and in vivo models of infection with single and double deletion mutations in $c a d B$ and $c a d A$. Our results uncover a vital role of $\operatorname{cadBA}$ operon in E. tarda survival under acidic stress environment and in host cells, and provide the first insights into the pathogenicity of the AR system in E. tarda.

\section{Materials and methods}

\section{Strains and culture conditions}

E. coli DH5a was purchased from TransGen (Beijing, China) and used for genetic manipulation. E. coli SM10 $\lambda$ pir or D1000 was purchased from Biomedal (Sevilla, Spain) and used for preparation of suicide vectors. $E$. tarda TX01 was isolated from diseased fish [33]. Bacteria were grown in Luria-Bertani (LB) broth or on LB agar at $37{ }^{\circ} \mathrm{C}$ (for $E$. coli) or $28^{\circ} \mathrm{C}$ (for $E$. tarda). When required, antibiotics were added to the media as follows: ampicillin (Amp), $100 \mu \mathrm{g} / \mathrm{mL}$; chloramphenicol $(\mathrm{Cm}), 30 \mu \mathrm{g} /$ $\mathrm{mL}$; polymyxin B (poly B) or colistin (Col), $100 \mu \mathrm{g} / \mathrm{mL}$; 
tetracycline (Tc), $20 \mu \mathrm{g} / \mathrm{mL}$ and kanamycin $(\mathrm{Km}), 50 \mu \mathrm{g} /$ $\mathrm{mL}$, respectively.

\section{Total RNA isolation, cDNA synthesis, and co-transcriptional} verification

The experiment was performed as previously reported [34]. Overnight cultures of E. tarda TX01 were grown in LB broth at $28{ }^{\circ} \mathrm{C}$ and used for RT-PCR. Total RNA was isolated using the HP Total RNA kit (Omega BioTek, USA) according to the manufacturer's instructions. cDNA synthesis was performed with Superscript II reverse transcriptase (Invitrogen, USA). The cadBA co-transcriptional fragment was located at the $3^{\prime}$ end of $c a d B$ and $5^{\prime}$ end of $c a d A$, and amplified with specific primers CadBAF and CadBAR using total RNA, cDNA, and genomic DNA as the template, respectively. The sequences of primers used are shown in Table 1.

\section{The expression of acid resistance genes under acidic conditions and in cadC mutant}

To study expression of acid resistance genes under exposure to acid stress conditions, the exponential phase cultures of TX01 were treated for $1 \mathrm{~h}$ in LB media supplemented with $5 \mathrm{mM}$ L-lysine ( $\mathrm{pH}$ 5.5) in static cultivation. Total RNA was extracted with an HP Total RNA kit (Omega Bio-Tek, USA) according to the manufacturer's instructions. cDNA synthesis was performed as described above. RT-qPCR was carried out as reported previously [35]. The relative transcriptional level of acidic resistance genes $(c a d C, \operatorname{cadB}, \operatorname{cad} A$, and $\operatorname{cadBA})$ in $E$. tard $a$ were determined using the $2^{-\triangle \triangle \mathrm{CT}}$ method with $16 \mathrm{~S}$ rRNA used as a reference gene.

\section{Constructions of mutant strains TX01 $\Delta c a d A$, TX01 $\Delta c a d B$, and TX01 $\triangle$ cadBA and plasmid-complemented strains TX01 $\triangle$ cadAC and TX01 $\triangle$ cadBC}

The constructions of mutants TX01 $\Delta c a d A$, TX01 $\Delta c a d B$, and TX01 $\triangle c a d B A$ and complementary strains TX01 $\triangle c a d A C$ and TX01 $\triangle c a d B C$ were performed as reported previously [35]. The primers used in this study are listed in Table 1. Primers CadAKOF1/CadAKOR1 and CadAKOF2/CadAKOR2 were used for the construction of TX01 $\Delta c a d A$ mutant, in which a $1023 \mathrm{bp}$ segment (517 to $1539 \mathrm{bp}$ in the ORF) in-frame deletion was created. Primers CadBKOF1/CadBKOR1 and CadBKOF2/CadBKOR2 were used for the construction of TX01 $\Delta c a d B$ mutant, in which a 636 bp segment (337 to $972 \mathrm{bp}$ in the ORF) in-frame deletion was created. The transconjugants were selected on LB agar plates supplemented with $10 \%$ sucrose. cadA single-knockout strain was named as TX01 $\Delta c a d A$, and $c a d B$ single-knockout strain was named as TX01 $\Delta c a d B$. A similar operation
Table 1 Oligonucleotide primers used in this study

\begin{tabular}{|c|c|}
\hline Primer name & Sequence $\left(5^{\prime}-3^{\prime}\right)$ \\
\hline CadAKOF1 & GGATCCCGCATTTTGCCTGGAGA (BamHI) \\
\hline CadAKOR1 & TTAGCCACGCCGTAGAAATCATAGAACA \\
\hline CadAKOF2 & TCTACGGCGTGGCTAAATACCTGGACG \\
\hline CadAKOR2 & GGATCCGGGTAGTGAGCACCGATTT (BamHI) \\
\hline CadAKOF3 & TCAGCGAGATGAACGAGCA \\
\hline CadAKOR3 & TGACCACGCAGTTCCATCT \\
\hline CadBKOF1 & GGATCCTATTGCGACACGCTGAG $($ BamHl) \\
\hline CadBKOR1 & CGGAAGCCGAAGAAGGTGGACAGGTA \\
\hline CadBKOF2 & CCTTCTTCGGCTTCCGTGAAAATGA \\
\hline CadBKOR2 & GGATCCCGAATGGGTTCTTCTTTGA (BamHI) \\
\hline CadBKOF3 & GAGGTTGGTCCTGCTTTTG \\
\hline CadBKOR3 & GAAGCGAATCAGGTCAACG \\
\hline CadBAPF1 & GATATCATTTGTATAATGATTGACCAC (ECORV) \\
\hline CadBAPR1 & GATATCGGTCAAGTTGCTCCTGATT (ECORV) \\
\hline CadBAPR2 & ATATTCATGGTCAAGTTGCTCCTGATT \\
\hline CadAF1 & ACTTGACCATGAATATTATTGCCATCCTG \\
\hline CadAR1 & GATATCTTACTTCTGTTCAGTTTTGAGC (ECORV) \\
\hline CadBR1 & 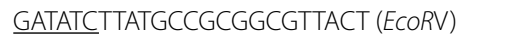 \\
\hline CadBAF & CCCGAAAGTTTACGGTGAGA \\
\hline CadBAR & GCAGGTGCTCGTTCATCTCG \\
\hline CadCRTF & GGTACTTGAGCCCAGACTCATCGA \\
\hline CadCRTR & GCACGGTCACGATATACTCTGGC \\
\hline CadBRTF & GCGCCATGTCACTGGCCTATGT \\
\hline CadBRTR & TTCAGCACCGAAGAAGGTGGACAG \\
\hline CadARTF & GCACGTCTGTGCGGCGTTATCT \\
\hline CadARTR & TTCAGCGCGATGTCTTCGGCTG \\
\hline CadBARTF & GAACAACAGTAACGCCGCGGCAT \\
\hline CadBARTR & CCCATGTGATTCAGGATGGCAATAATATTC \\
\hline 3006RTF & CTCGCCGACCTTCAAGCGGATT \\
\hline 3006RTR & CAGCATTTCGTTCAGCGCCGTGAT \\
\hline 1884RTF & CTTGGTCGGTGCAATGTCGCTG \\
\hline 1884RTR & GGAAGAAGACCGACAGATAGGCG \\
\hline
\end{tabular}

was carried out to construct the double-knockout strain $\mathrm{TX} 01 \triangle c a d B A$.

For construction of TX01 $\Delta c a d A$ complementary strain, a 2145-bp cadA coding region and 418-bp putative promoter region were cloned with primers CadAF1/CadAR1 and CadBAPF1/CadBAPR2, respectively. Two DNA fragments were fused together by overlapping PCR with CadBAPF1/CadAR1 and verified by sequencing. The fused PCR fragment was digested with EcoRV, ligated into plasmid pJR21 digested with PmeI. The resulting plasmid was transformed into TX01 $\triangle c a d A$ by conjugation transfer. The complementary strain TX01 $\Delta c a d A C$ was screened on LB agar plates supplemented with $100 \mu \mathrm{g} /$ $\mathrm{mL}$ polymyxin $\mathrm{B}$ and $20 \mu \mathrm{g} / \mathrm{mL}$ tetracycline, and further confirmed by PCR. For construction of TX01 $\Delta c a d B$ 
complementary strain, a 1332-bp cadB coding region and a 418-bp upstream of transcriptional start site was amplified from TX01 with primers CadBAPF1/CadBR1. The following experimental operations are similar to the construction of TX01 $\triangle$ cadAC. The complementary strains were named as TX01 $\triangle c a d A C$ and TX01 $\triangle c a d B C$, respectively.

\section{Resistance to environmental stresses}

The overnight cultures of TX01, TX01 $\Delta c a d A$, TX01 $\Delta c a d B$ and TX01 $\Delta c a d B A$ were grown in LB media, diluted to a final concentration of about $10^{5} \mathrm{CFU} / \mathrm{mL}$. For acid stress, aliquots of $(200 \mu \mathrm{L})$ cultures in LB broth at $\mathrm{pH}$ gradients (from 7.0 to 4.5 ) were distributed into the wells of Bioscreen $\mathrm{C}$ plate. For the iron deficiency assay, bacteria were added into fresh LB media with $50 \mu \mathrm{M}$ of 2, 2'-dipyridyl (Dp). For oxidation stress assay, bacteria were added into fresh LB media with $500 \mu \mathrm{M}$ of diamide. Growth curves were monitored at 2-h intervals through the measurement of the absorbance at $600 \mathrm{~nm}$ using Bioscreen C Automated Growth Curve System (OyGrowth Curves Ab Ltd, Finland).

\section{Lysine decarboxylase assay}

Lysine decarboxylase broth was purchased from Hopebio (Qingdao, China) and used for the lysine decarboxylase (LDC) qualitative measurement. Various overnight cultures of bacteria (TX01, TX01 $\Delta c a d A$, TX01 $\Delta c a d B$, $\mathrm{TX} 01 \Delta c a d B A, \mathrm{TX} 01 \Delta c a d A C$ and $\mathrm{TX} 01 \Delta c a d B C$ ) were diluted to an optical density of 0.5 at $600 \mathrm{~nm}$. A $50-\mu \mathrm{L}$ aliquot of the cultures were inoculated into lysine decarboxylase broth after being washed two times and resuspended with sterile water. Sterile paraffin-coated liquid $(300 \mu \mathrm{L})$ was then added into inoculated media to create an anaerobic environment and the cultures were incubated at $28{ }^{\circ} \mathrm{C}$ for 10,20 and $30 \mathrm{~h}$. Lysine decarboxylase broth without L-lysine was taken as a blank control. A positive test is indicated if the control tube is yellow and the LDC-positive tube is purple or red brown color. On the contrary, a negative test is indicated if both the control tube and the LDC-positive tube are yellow.

Strains were grown in LB broth at $28{ }^{\circ} \mathrm{C}$ until $\mathrm{OD}_{600}$ of 0.5. Culture aliquots were collected and normalized to an $\mathrm{OD}_{600}$ of 1.0. Quantification of lysine decarboxylase activity was then carried out as described previously [36]. Lysine decarboxylase activity is a measure of lysine converted to cadaverine per time ( $\mathrm{min}$ ) per unit cell density, and was determined by $A_{340}$ between the sample incubated with or without lysine using the following equation:

$$
\left[A 340 /\left(\text { time } \times \mathrm{OD}_{600}\right)\right] \times 1000 .
$$

\section{Biofilm assay}

Biofilm formation was assayed using crystal violet staining as previously described [37]. Overnight cultures of TX01, TX01 $\Delta c a d A, \mathrm{TX} 01 \Delta c a d B, \mathrm{TX} 01 \Delta c a d B A$, TX01 $\triangle c a d A C$ and TX01 $\triangle c a d B C$ were grown in LB media, diluted to $10^{5} \mathrm{CFU} / \mathrm{mL}$, and then resuspended in $\mathrm{LB}$ media at $\mathrm{pH} 7.0$ and 5.5. $200 \mu \mathrm{L}$ of cultures were transferred into 96-well polystyrene plates and incubated at $28{ }^{\circ} \mathrm{C}$ for $24 \mathrm{~h}$ under static conditions. The media and planktonic cells were discarded after culture and the wells were washed three times with PBS. The adhered cells were treated with Bouin fixative (Solarbio, China) for $1 \mathrm{~h}$ and then stained with $1 \%$ crystal violet (CV, Sigma) solution for $20 \mathrm{~min}$, followed by the removal of unbound crystal violet by washing several times with PBS. The CV bound to biofilm was solubilized with $200 \mu \mathrm{L}$ methanol and absorbance was measured at $570 \mathrm{~nm}$.

For confocal laser scanning microscopy (CLSM) observation, TX01, TX01 $\triangle c a d A, T X 01 \Delta c a d B$ and TX01 $\triangle$ cadBA were cultured in LB broth on glass-bottom dishes at $28{ }^{\circ} \mathrm{C}$ for $24 \mathrm{~h}$. Non-adherent cells and culture fluid were removed and washed three times with PBS. The biofilms were stained with a LIVE/DEAD BacLight bacterial viability kit L-13152 (Invitrogen-Molecular Probes, USA) for $15 \mathrm{~min}$ at room temperature in dark conditions. The fluorescent images were acquired using a FV1000 confocal laser scanning microscope (Olympus, Japan).

\section{Motility assays}

Swimming motility assays were performed using swimming plates which contain LB media with $0.3 \%$ (W/V) agar at $\mathrm{pH} 7.0$ or $\mathrm{pH}$ 5.5. Overnight cultures of TX01, TX01 $\Delta c a d A, T X 01 \Delta c a d B$, TX01 $\Delta c a d B A, T X 01 \Delta c a d A C$ and TX01 $\triangle c a d B C$ were cultured in LB media to an $\mathrm{OD}_{600}$ of 0.5 . Aliquots of $(1 \mu \mathrm{L})$ cell suspensions were inoculated into swimming plates by submerging pipette tips in the cultures and pricking the center of the plates. Plates were then incubated for $18 \mathrm{~h}$, and the swimming motility zone was measured.

\section{Invasion of eukaryotic cell lines}

The human cervical epithelial cell line HeLa and the murine monocyte-macrophage cell line RAW264.7 were cultured in Dulbecco Modified Eagle medium (DMEM) supplemented with $10 \%(\mathrm{~V} / \mathrm{V})$ fetal bovine serum (FBS, Sigma), $100 \mathrm{U} / \mathrm{mL}$ penicillin G (Sigma), and $100 \mu \mathrm{g} / \mathrm{mL}$ streptomycin (Sigma) at $37^{\circ} \mathrm{C}$ with $5 \% \mathrm{CO}_{2}$.

The interaction of E. tarda and host cells was studied as reported previously [38]. Briefly, E. tarda TX01, TX01 $\Delta c a d A, T X 01 \Delta c a d B, T X 01 \Delta c a d B A, T X 01 \Delta c a d A C$, and TX01 $\triangle c a d B C$ strains were grown in LB broth at 
$30{ }^{\circ} \mathrm{C}$ and then transferred into DMEM without shaking until the optical density at $600 \mathrm{~nm}$ reached 1.0. HeLa cells were seeded and cultured in 96-well cell culture plates, and infected with $100 \mu \mathrm{L}$ of $E$. tarda at a multiplicity of infection (MOI) of 10:1. To detect bacterial adhesion, after incubation at $28{ }^{\circ} \mathrm{C}$ for 1 and $2 \mathrm{~h}$, the monolayers were washed three times with PBS and lysed with 200 $\mu \mathrm{L}$ of $1 \%(\mathrm{~V} / \mathrm{V})$ Triton X-100 for $10 \mathrm{~min}$; series diluted bacteria were quantified by LB agar plates supplemented with polymyxin $B$.

Bacterial replication in RAW264.7 cells was performed as previously [39]. Briefly, RAW264.7 cells were infected with $100 \mu \mathrm{L}$ E. tarda strains at MOI of 10:1. The monolayers were washed with $\mathrm{PBS}$ and then in cultured DMEM containing $200 \mu \mathrm{g} / \mathrm{mL}$ of gentamicin for $2 \mathrm{~h}$ to kill the extracellular bacteria, then they were maintained in DMEM including $10 \mu \mathrm{g} / \mathrm{mL}$ of gentamicin for $1 \mathrm{~h}$. Subsequently, the cultures were incubated at $28^{\circ} \mathrm{C}$ for $0,2,4$, and $8 \mathrm{~h}$. The monolayers were washed three times with PBS and lysed with $1 \%(\mathrm{~V} / \mathrm{V})$ Triton X-100 for enumeration.

For microscopy observation, E. tarda was transformed with plasmid $\mathrm{pGFP}_{\mathrm{UV}}$ expressing green fluorescence protein by electroporation using Gemini Twin Wave Electroporators [40]. RAW264.7 cells were cultured in glass-bottom dishes and infected with TX01, TX01 $\Delta c a d A, T X 01 \Delta c a d B$ and TX01 $\triangle c a d B A$ strains possessing the pGFP ${ }_{\mathrm{UV}}$ plasmid at $30^{\circ} \mathrm{C}$ for 0,2 , and $4 \mathrm{~h}$. The cells were washed three times with PBS and fixed by polyformaldehyde for $30 \mathrm{~min}$, and then labeled with DAPI (Solarbio, China). The cells were observed by a confocal microscope (Olympus Fluoview FV1000, Japan) after washing three times with PBS.

\section{Fish and experimental challenges for bacterial dissemination in vivo}

Healthy Tilapias (average weight $13.0 \mathrm{~g}$ ) were purchased from a commercial fish farm in Haikou, and fed in aerated water at $25 \pm 1{ }^{\circ} \mathrm{C}$ for 2 weeks. Before the experiment, the fish were randomly sampled and checked for the presence of bacteria in the blood, liver, kidney and spleen. For tissue dissemination analysis, TX01, $\mathrm{TX} 01 \Delta c a d A$, TX01 $\Delta c a d B, \mathrm{TX} 01 \Delta c a d B A$, TX01 $\Delta c a d A C$, and TX01 $\triangle c a d B C$ were cultured in LB broth to an $\mathrm{OD}_{600}$ of 0.5 . The cells were washed with PBS and resuspended in PBS to $10^{7} \mathrm{CFU} / \mathrm{mL}$. Tilapia were divided randomly into six groups and infected by intramuscular (i. m.) injection with $50 \mu \mathrm{L}$ of various bacterial suspensions, respectively. Fish were euthanized with an overdose of MS222 (tricaine methanesulfonate) (Sigma, USA) at 24 and $48 \mathrm{~h}$ post-infection. Subsequently the spleen and kidney of the fish were taken aseptically, and the recoveries of bacteria in the tissues were determined as previously [39]. The assay was performed in triplicate.

\section{Transcriptional regulation of cadBA by CadC}

In the study of cadC, we obtained cadC mutant $\mathrm{TX} 01 \Delta c a d C$. The expression of $c a d B A$ operon in TX01 and TX01 $\Delta c a d C$ at acid condition was examined by RTqPCR. To examine $c a d B A$ expression in in vitro conditions, the speculative promoter of $c a d B A$ (the $418 \mathrm{bp}$ DNA upstream of $c a d B A$ operon), P418, was cloned with primers CadBAPF1/CadBAPR1 and was inserted into the $B a m H I$ site of pSC11, a promoter probe plasmid [41], which resulted in pSC418. pSC418 and pJR21C which expressed the CadC were introduced into E. coli $\mathrm{DH} 5 \alpha$ by co-transformation, and cultured on X-gal (5-bromo-4-chloro-3-indolyl-beta-D-galactopyranoside) plate. Meanwhile, pJR21 was used as the control. To study the transcriptional regulation of $\mathrm{P} 418$ by $\mathrm{CadC}$ in vivo, the amplified P418 fragment was inserted into the SmaI site of p181-lux, a promoter probe plasmid based on pACYC177 and pGL28. The resulting plasmid was digested with SmiI and the fragment that included P418 and luciferase gene was inserted into the PmeI site of pJR21, resulting in pJR21-418-lx. pJR21-418-lx was introduced into TX01 and TX01 $\Delta c a d C$ which is the cadC mutant by electro-transformation, respectively. The transformants were screened on LB agar plates supplemented with $100 \mu \mathrm{g} / \mathrm{mL}$ polymyxin $\mathrm{B}$ and $20 \mu \mathrm{g} / \mathrm{mL}$ tetracycline. The log-phase transformants were cultured in normal conditions $(\mathrm{pH}=7.0)$ or in $\mathrm{LB}$ broth $(\mathrm{pH}=5.5)$ with $5 \mathrm{mM} \mathrm{L}$-lysine for $1 \mathrm{~h}$, and subjected to luciferase assay using the Firefly Luciferase Reporter Gene Assay Kit (Beyotime, China).

\section{Statistical analysis}

All data were analyzed statistically using the analysis of variance (ANOVA) with SPSS 18.0 software (SPSS Inc., Chicago, IL, USA), and $P<0.05$ was considered statistically significant. Each experiment was performed three times, data are presented as the means $\pm \operatorname{SEM}(N=3) . N$, the number of times the experiment was performed. Statistical significance $\left(*, P<0.05 ;{ }^{* *}, P<0.01\right)$ was obtained using an ANOVA test with SPSS 18.0 software (SPSS Inc., Chicago, IL, USA).

\section{Results}

Characterization of $c a d B A$ operon sequence and its co-transcription verification

Although some genes or factors were identified to contribute to acid resistance of $E$. tarda, there is not any report on the classical acid resistance systems in E. tarda. In order to further explore E. tarda's mechanism of acid resistance, a lysine-dependent acid resistance (LDAR) 
system, CadBA, was identified and characterized in this study. The $c a d B$ of E. tarda (ETAE_0756) consists of $1332 \mathrm{bp}$ ORF that encodes a lysine/cadaverine antiporter composed of 443 amino acids with a calculated molecular mass of $46.1 \mathrm{kDa}$ and a theoretical pI of 9.01. Structural analysis suggested that $\mathrm{CadB}$ is a membrane protein with 12 transmembrane helices. Multiple sequence alignment shows that $\mathrm{CadB}$ shares high overall amino acid sequence identities (66-84\%) with lysine/cadaverine antiporter homologues of Salmonella enterica, Klebsiella pneumoniae, E. coli, Shigella flexneri, Vibrio cholerae, and Aeromonas veronii (Additional file 1).

The cadA of E. tarda (ETAE_0757) consists of $2145 \mathrm{bp}$ ORF that encodes a lysine decarboxylase composed of 714 amino acids with a calculated molecular mass of $81.0 \mathrm{kDa}$ and a theoretical pI of 5.53. CadA includes an $\mathrm{N}$-terminal domain (residues 14 to 124), a PLP-binding core domain (residues 131 to 441), and a C-terminal domain (residues 571 to 695), which contains a pyridoxal phosphate binding motif formed by 15 residues. Multiple sequence alignment showed that CadA shares high overall amino acid sequence identities (70-86\%) with lysine decarboxylase homologues of $E$. coli, Salamae, A. veronii, V. cholerae, K. pneumoniae, and Shigella boydii (Additional file 1).

The $c a d B$ and $c a d A$ of numerous bacteria such as E. coli, V. cholerae, S. typhimurium are co-transcribed under one operon, providing advantages to counter low intracellular and extracellular pH. In E. tarda, there is a 148 bp intergenic spacer region between $c a d B$ and $c a d A$ (Figure 1A). To verify whether the two genes are co-transcribed, a pair of primers annealing to the $3^{\prime}$ end of $c a d B$ and $5^{\prime}$ end of $c a d A$ was designed. PCR was performed using total RNA, complementary DNA (cDNA), and genomic DNA (gDNA) of E. tarda as templates, respectively. The results show that the predicted PCR product of $795 \mathrm{bp}$ was amplified in the reaction using $\mathrm{CDNA}$ and gDNA, but not in RNA (Figure 1B), which indicates that $c a d B$ and $c a d A$ are co-transcribed under one operon. The operon is named as $c a d B A$. The upstream gene of the $c a d B A$ operon is a $c a d C$ encoded transcriptional regulator, and there is a predictive promoter between $c a d B$ and cadC, Pcad (Figure 1A).

\section{Constructions of mutant strains TX01 $\Delta c a d A, T X 01 \Delta c a d B$, and TX01 $\triangle$ cadBA and complementary strains TX01 $\triangle$ cadAC, and TX01 $\triangle \mathrm{cadBC}$}

To verify the function of the $\operatorname{cadBA}$ operon, the $\operatorname{cad} A$ and $c a d B$ genes were knocked out by markerless in-frame deletion of region encoding amino acid residues 173 to 513 and 113 to 324, respectively. Meanwhile, the whole operon was also knocked out by markerless in-frame deletion of the region from the N-terminal 113 amino

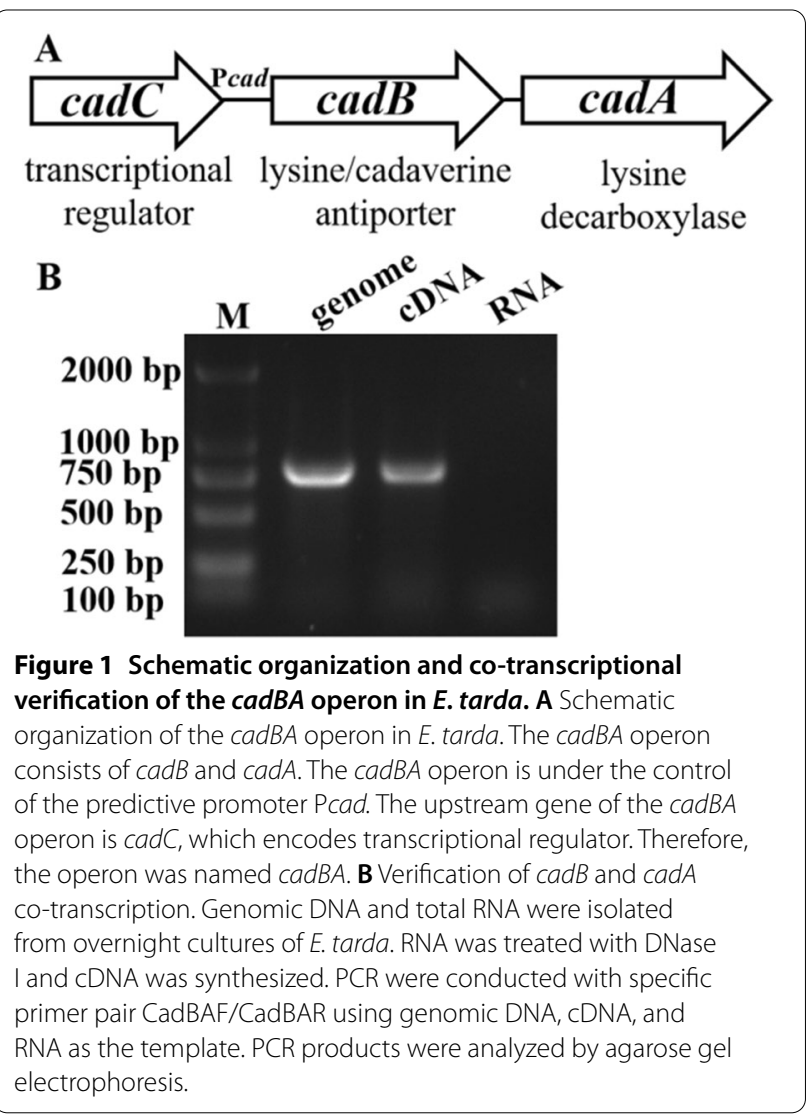

acid residues of $\mathrm{CadB}$ to $\mathrm{C}$-terminal 202 amino acid residues of CadA. Deletion of the genes were verified by PCR with specific primers and sequencing (Additional file 2). The resulting mutants were named TX01 $\Delta c a d A$, $\mathrm{TX} 01 \Delta c a d B$, and TX01 $\operatorname{cadBA}$. The genetic complementation of TX01 $\Delta c a d A$ and TX01 $\Delta c a d B$, TX01 $\Delta c a d A C$ and TX01 $\operatorname{cadBC}$, were also obtained.

\section{cadBA is involved in adversity resistance}

In the process of infecting the host or host cell, pathogens inevitably face some environmental pressures, such as acid stress, iron deficiency, and oxidative stress. Previous studies indicated that $\operatorname{cadBA}$ operon in several bacteria were essential for physiological fitness to acid stress. We want to know whether $\operatorname{cadBA}$ in E. tarda has any effects on bacterial resistance to acid stress and some other environmental pressures. For this purpose, wild type strain TX01, cadBA operon deletion mutant strains TX01 $\Delta c a d A$, TX01 $\Delta c a d B$, and TX01 $\operatorname{cadBA}$ were cultured in LB broth with a pH range of 7.0 to 4.5. No difference was observed between the growth characteristics of the wild-type and three mutants under normal conditions $(\mathrm{pH}=7.0)$ (Figure 2A). When exposed to the acidic environment $(\mathrm{pH}=5.5$ to 4.5 ), the growths of 


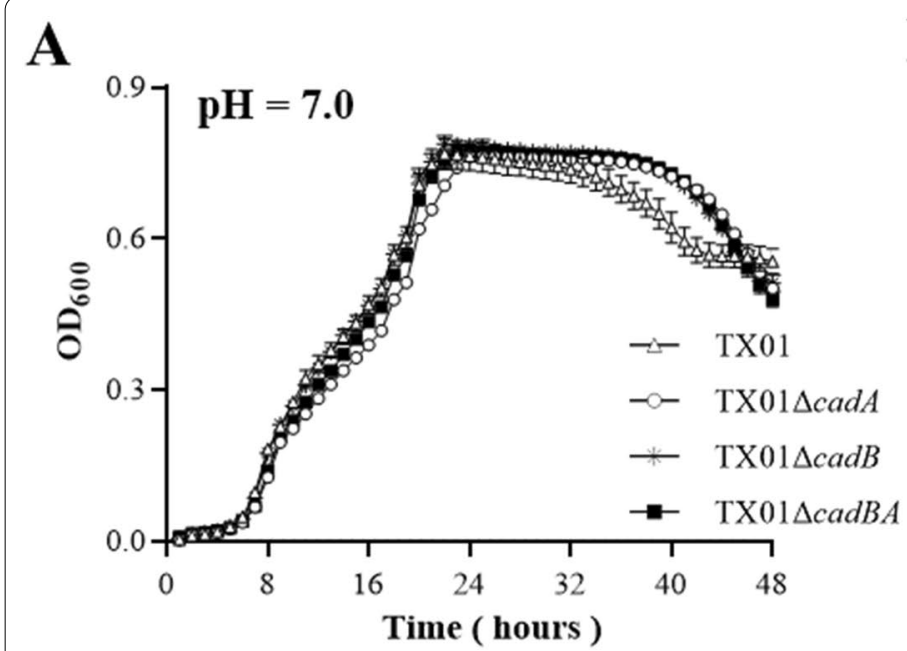

B

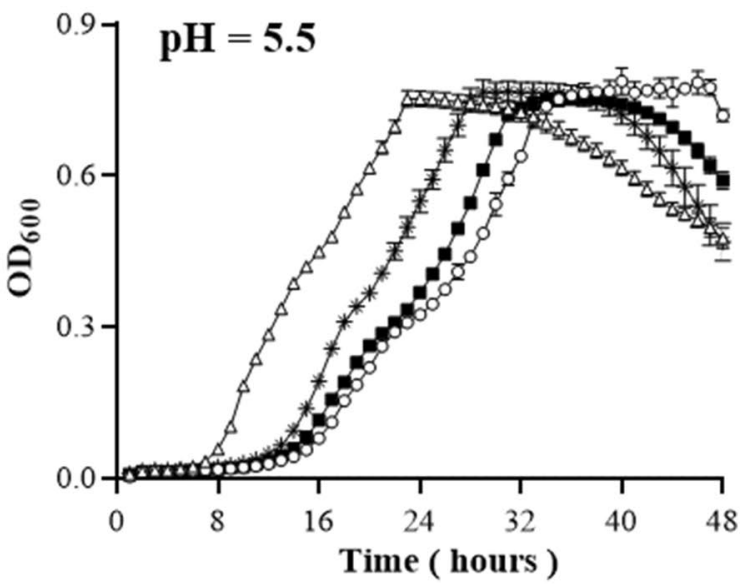

C

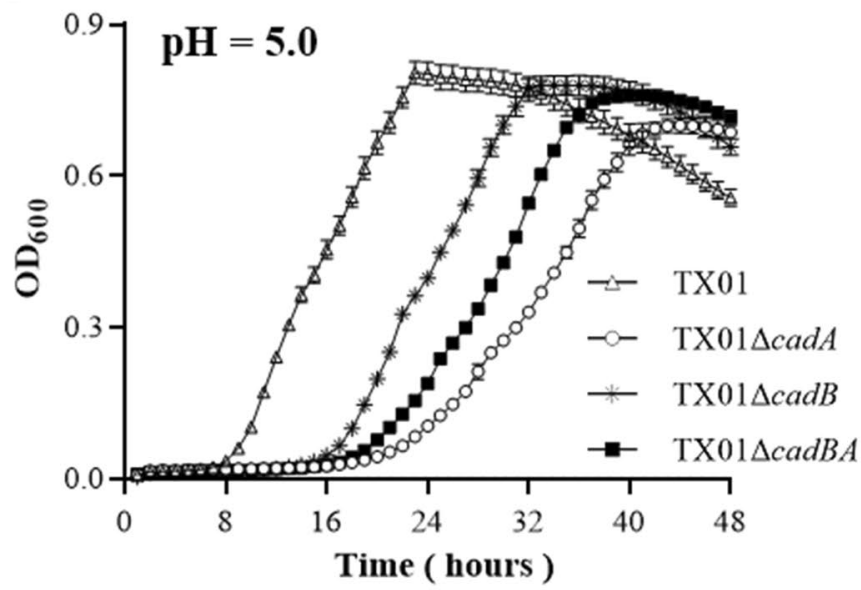

D

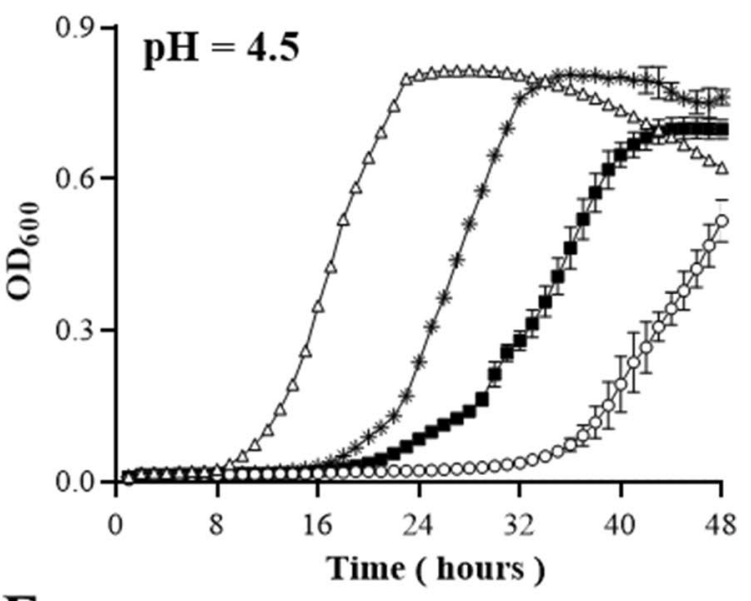

$\mathbf{E}$

$\mathbf{F}$
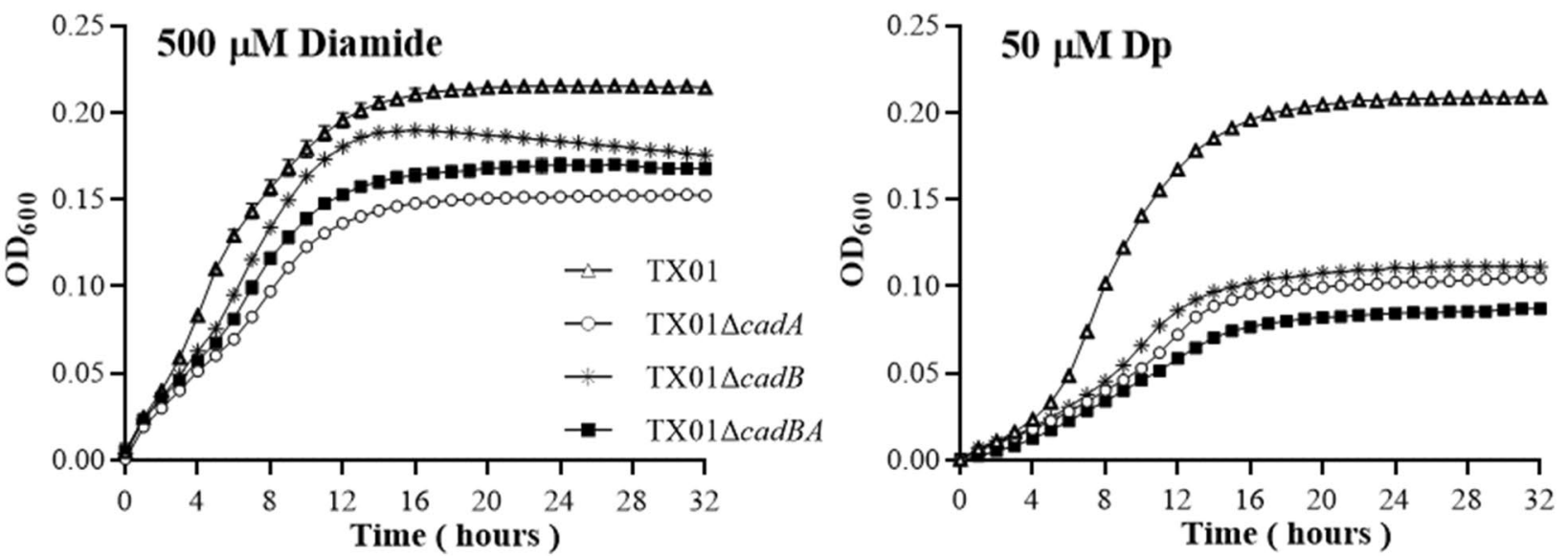

Figure 2 Growth analysis of $E$. tarda in different conditions. The wild-type TX01, its isogenic cadA, cadB and cadBA deletion mutant strains $T X 01 \triangle c a d A, T X 01 \triangle c a d B$, and TX01 $\triangle c a d B A$ were cultured to the exponential phase. After diluting serially, bacteria were cultured in fresh LB broth with $\mathrm{pH}$ adjusted to 7.0, 5.5, 5.0, and 4.5 (A-D). Bacteria were added into fresh medium with $500 \mu \mathrm{M}$ of diamide (E) and $50 \mu \mathrm{M}$ of 2,2'-dipyridyl (Dp) $(\mathbf{F})$, respectively. Cell density was monitored at 2-h intervals by measuring the $\mathrm{OD}_{600}$. Experiment was performed three times, data are presented as the means $\pm \operatorname{SEM}(N=3)$. $N$, the number of times the experiment was performed. 
four strains were retarded to varying degrees. Compared to wild type strain TX01, three mutants were obviously retarded. TX01 $\triangle$ cadA was most affected by acid stress, followed by TX01 $\Delta c a d B A$ and TX01 $\Delta c a d B$, but the cell densities of three mutants were similar to that of TX01 at the stationary phase (Figures $2 \mathrm{~B}-\mathrm{D}$ ). When the $\mathrm{pH}$ of the medium adjusted to $\mathrm{pH} 4.0$, mutants failed to grow (data not shown).

When grown in LB medium containing $500 \mu \mathrm{M}$ of oxidant diamide, the growths of four strains were retarded and three mutants displayed slightly slower growth rates than TX01 (Figure 2E). When grown in LB medium containing $50 \mu \mathrm{M}$ of dipyridyl (a kind of iron chelator), the growths of four strains were retarded and three mutants displayed obviously slower growth rates than TX01, but there was no obvious difference of growth amongst three mutants (Figure 2F). These results suggest that the deletion of $c a d A$ or $c a d B$ does not impair the growth of $E$. tarda under normal conditions, but to a certain extent, affects bacterial growth under iron deficiency and oxidative stress, especially under acid stress.

\section{cadBA participates in lysine metabolism}

The inducible lysine decarboxylase can convert lysine to cadaverine, which plays an important role in $\mathrm{pH}$ homeostasis by neutralizing the acidic by-products of carbohydrate fermentation. In order to explore the mechanism that $c a d B A$ contributes to acid tolerance of $E$. tarda, we examined the effect of $c a d B A$ on activity of lysine decarboxylase. The LDC assay was performed and the result of qualitative measurement shows that TX01 exhibited observable purple after incubation in static culture for $10 \mathrm{~h}$, which indicates an LDC positive phenotype (Figure 3A). However, three mutants exhibited faint yellow or light color, which indicates an LDC negative phenotype. After culturing for $20 \mathrm{~h}$, TX01 exhibited a stronger purple and TX01 $\Delta c a d A$ and TX01 $\Delta c a d B$ displayed observable purple, but TX01 $\triangle c a d B A$ remained faint yellow. When culturing time reaches $30 \mathrm{~h}$, all four strains displayed different degrees of purple. Complementary strains TX01 $\Delta c a d A C$ and TX01 $\triangle c a d B C$ could partially recover the positive phenotype of lysine decarboxylase (Figure 3A). The quantitative assays revealed that the lysine decarboxylase activity in the mutant TX01 $\triangle$ cadA, $\mathrm{TX} 01 \Delta c a d B$, and TX01 $\operatorname{cadBA}$ was $10.1,26.2,3.4 \mathrm{U}$, respectively, which all are significantly lower than that in TX01 (34.6 U). Among the three mutants, the lysine decarboxylase activity of TX01 $\triangle$ cadBA was significantly lower than that of TX01 $\Delta c a d A$, and the latter was significantly lower than that of TX01 $\Delta c a d B$ (Figure $3 B$ ). The lysine decarboxylase activity of complementary strain TX01 $\triangle c a d B C$ was similar to that of TX01, while that of complementary strain TX01 $\triangle$ cadAC was dramatically

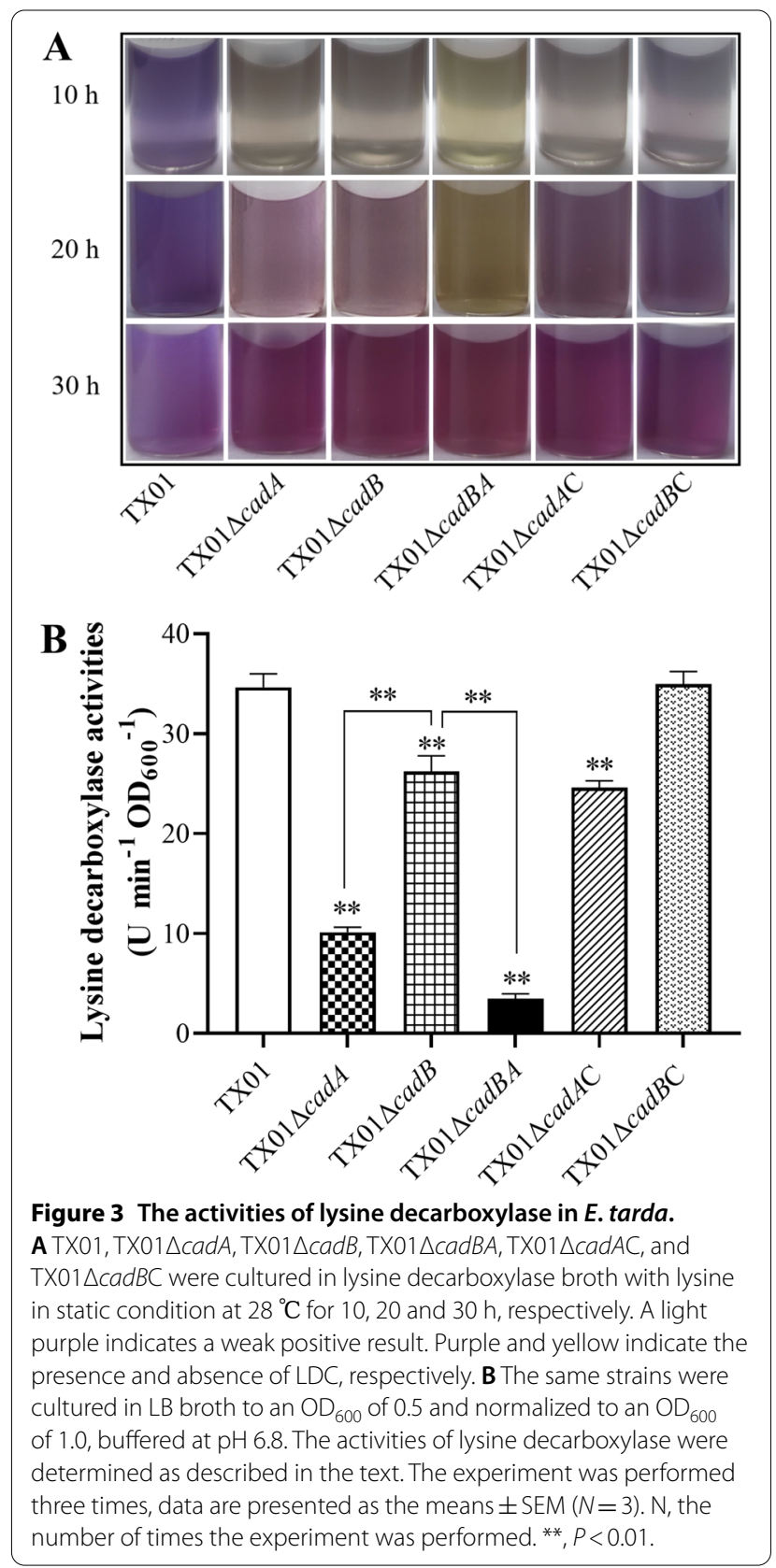

higher than that of TX01 $\Delta c a d A$ but a little lower than that of TX01 (Figure 3B).

\section{cadBA mutations enhance bacterial biofilm formation, notably under acid conditions}

Bacterial growth in biofilm mode enhances microbial survival and safeguards them from environmental stresses, including acid stress. We want to know whether the defect in acid tolerance caused by the deletion of $c a d B A$ affects bacterial biofilm growth, so the biofilm formations of TX01, TX01 $\Delta c a d A$, TX01 $\Delta c a d B$, 


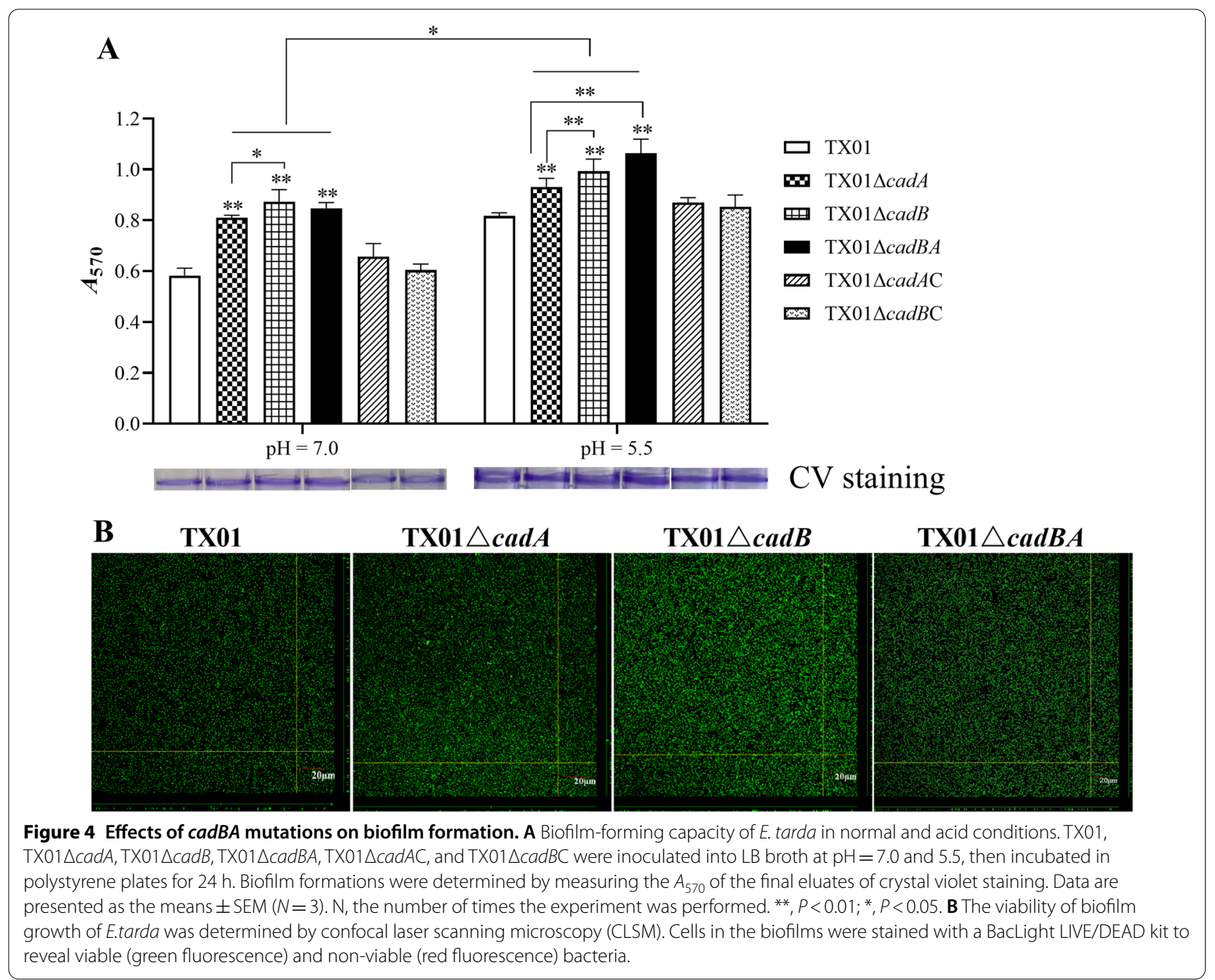

TX01 $\operatorname{cadBA}, \quad \mathrm{TX} 01 \Delta c a d A C$, and TX01 $\Delta c a d B C$ were determined by $\mathrm{CV}$ staining. As shown in Figure $4 \mathrm{~A}$, the biofilm forming capabilities of TX01 $\triangle c a d A$, $\mathrm{TX} 01 \Delta c a d B$, and TX01 $\triangle c a d B A$ were significantly stronger than that of TX01 when bacteria were cultured in normal LB medium $(\mathrm{pH}=7.0)$ for $24 \mathrm{~h}$. Consistently, images of the biofilms of four strains obtained by confocal laser scanning microscopy (CLSM) also showed that thicknesses and densities of the biofilm of three mutants were stronger than the wild type, and thickness and density of TX01 $\triangle c a d B$ was the strongest amongst three mutants (Figure 4B). When bacteria were cultured in acid $\mathrm{LB}$ medium $(\mathrm{pH}=5.5)$, the biofilm growths of all the strains exhibited a significant increase, especially TX01 $\Delta c a d B A$, compared to those in normal medium (Figure 4A). The complementary strains TX01 $\triangle c a d A C$ and TX01 $\triangle c a d B C$ restored the capacity of biofilm formation of TX01 $\Delta c a d A$, and $\mathrm{TX} 01 \Delta c a d B$, respectively. These results suggest that
cadBA negatively participates in biofilm formation, especially under acid conditions.

\section{cadBA mutations impair bacterial motility under acid conditions}

To investigate whether deletion of $c a d B A$ has any effect on bacterial motility, six strains were inoculated into swimming plates and bacterial motilities were observed for $18 \mathrm{~h}$. The swimming assay shows that on the neutral LB plate, TX01 and three mutants exhibited similar and little swimming zones (Figure 5A). However, in the acid swimming plate except TX01 $\Delta c a d A$, motility remained weak, other three strains' moveability were obviously enhanced (Figure 5B), but the swimming zones of TX01 $\Delta c a d B$ and TX01 $\triangle c a d B A$ were significantly shorter than that of TX01 (Figure 5C). The swimming zone of complementary strain TX01 $\triangle c a d B C$ was comparative to that of TX01, while the swimming zone of complementary strain TX01 $\triangle c a d A C$ was shorter than that of 


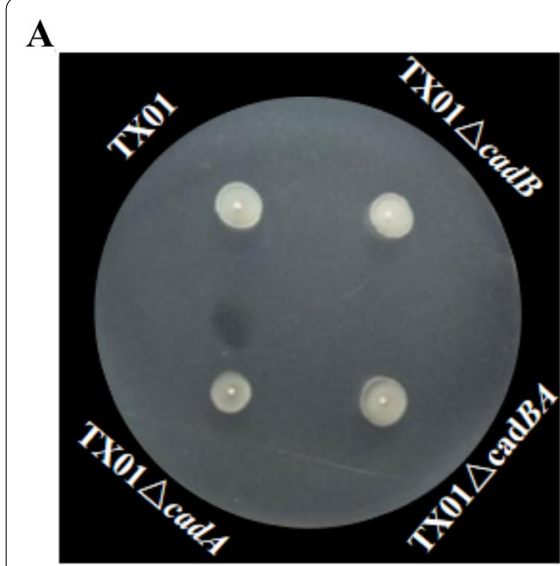

B

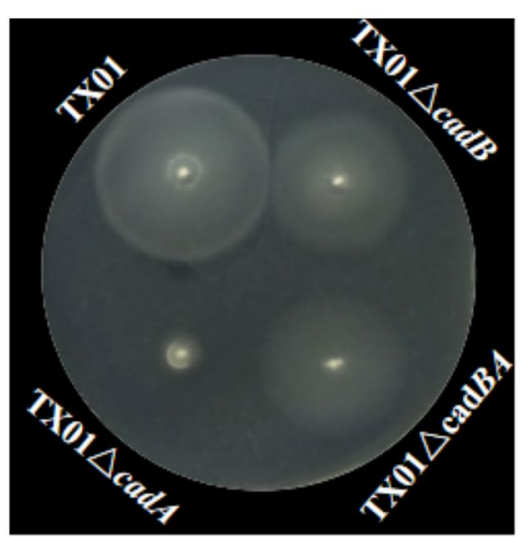

C

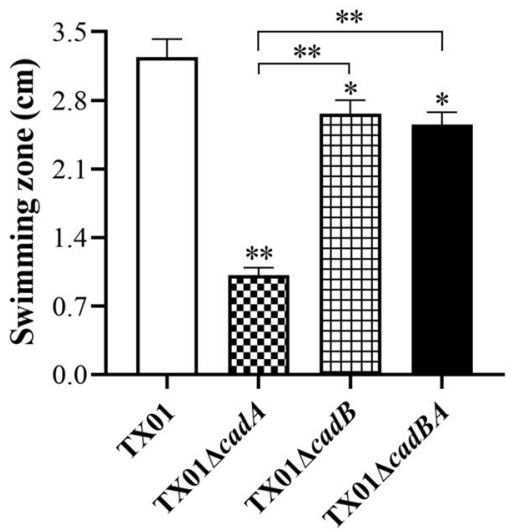

Figure 5 Effects of $c a d B A$ mutations on motility of E. tarda. TX01, TX01 $\triangle c a d A$, TX01 $\triangle c a d B$, and TX01 $\triangle$ cadBA were cultured in LB medium to an $\mathrm{OD}_{600}$ of 0.5 , then aliquots of cell suspensions $(1 \mu \mathrm{L}$ ) were inoculated into the center of swimming plates including $0.3 \%$ (W/N) agar with $\mathrm{pH}=7.0(\mathbf{A})$ or $\mathrm{pH}=5.5(\mathbf{B})$ at $28^{\circ} \mathrm{C}$ for $18 \mathrm{~h}$. C, The diameter of the swimming zone from the swimming plate at $\mathrm{pH}=5.5$. Data are presented as the means \pm SEM $(N=3)$. $N$, the number of times the experiment was performed. ${ }^{* *}, P<0.01 ;{ }^{*}, P<0.05$.

TX01 (Additional file 3), which indicates TX01 $\Delta$ cadAC could have partially recovered swimming ability in the acid swimming plate. These results suggest that $\operatorname{cadBA}$ operon mutations impair E. tarda's motility under acid conditions.

\section{cadBA deletions reduce the ability of adhesion and invasion to HeLa cells}

The above results show that the deficiency of $\operatorname{cadBA}$ increased E. tarda's biofilm formation but decreased motility in an acid environment, and reduced adversity resistance. These physiological phenotypes are all related to bacterial pathogenicity, so we want to know whether the deletion of $\operatorname{cadBA}$ could affect the virulence of $E$. tarda. To evaluate the participation of $c a d B A$ operon in the virulence of $E$. tarda, HeLa cells were infected with the same dose of TX01 $\Delta c a d A$, TX01 $\Delta c a d B$, $\mathrm{TX} 01 \Delta c a d B A$, TX01 $\Delta c a d A C$, and TX01 $\Delta c a d B C$ strains for 1 and $2 \mathrm{~h}$, then were washed three times and lysed. The bacteria adhering to the surface of cells and invading into the interior were examined. The results of plate counting indicate that the amounts of TX01 $\Delta c a d A$, $\mathrm{TX} 01 \Delta c a d B$, and TX01 $\Delta c a d B A$ from HeLa cells were remarkably less than that of TX01 at 1 and $2 \mathrm{~h}$ post-infection, and the amounts of TX01 $\triangle c a d A$ and TX01 $\triangle c a d B A$ from HeLa cells were also significantly less than that of TX01 $\triangle c a d B$ at both time points (Figure 6A). The amounts of complementary strain TX01 $\triangle$ cadAC from HeLa cells were comparative to those of TX01. However, the amount of complementary strain TX01 $\Delta c a d B C$ from HeLa cells was more than that of TX01 at $1 \mathrm{~h}$ postinfection, but the amounts of both were comparative at $2 \mathrm{~h}$ post-infection. These observations suggest that the mutations of $\operatorname{cadBA}$ impair the adhesion and invasion of E. tarda to non-phagocytes.

\section{cadBA is required for bacterial survival and replication in macrophages}

E. tarda prefers an intracellular lifestyle in host cells to escape the innate immunity and to multiply. Next, we examined the role of $c a d B A$ in phagocyte survival and replication of $E$. tarda. The same dose of TX01, TX01 $\Delta c a d A, \quad \mathrm{TX} 01 \Delta c a d B, \quad \mathrm{TX} 01 \Delta c a d B A$, TX01 $\triangle c a d A C$, and TX01 $\triangle c a d B C$ were used to infect murine macrophage cell line RAW264.7. After eliminating extracellular bacteria, RAW264.7 cells were cultured for different hours and were lysed to determine the intracellular bacteria. From the results of plate counting, we found that the amounts of TX01 $\Delta c a d A$, $\mathrm{TX} 01 \Delta c a d B$ and TX01 $\triangle c a d B A$ from the intracellular macrophage cells were remarkably less than those of TX01 at $0,2,4$, and $8 \mathrm{~h}$ post-infection, and the amount of TX01 $\triangle \mathrm{cadBA}$ was basically the least amongst the three mutants (Figure 6B). The amounts of complementary strains TX01 $\triangle$ cadAC and TX01 $\triangle c a d B C$ from the intracellular macrophage cells were similar to those of TX01.

To observe the living bacteria in macrophages, $E$. tarda containing pGFPuv plasmid was used to infect RAW264.7 cells. By means of confocal microscopy, it was clearly observed that the fluorescence intensities from TX01 $\Delta c a d A-$, TX01 $\Delta c a d B-$, and TX01 $c a d B A-$ infected macrophages were weaker than those from TX01-infected cells at 0,2 and $4 \mathrm{~h}$ post-infection (Figure $6 \mathrm{C}$ ). These results suggest that the mutations of 
cadBA impair the survival and replication of E. tarda in host phagocytes.

\section{cadBA is a requisite for bacterial dissemination in host tissues}

An in vitro experiment has confirmed the participation of $c a d B A$ operon in E. tarda's invasion of host cells. Next, in vivo experiments were performed to determine the contribution of $c a d B A$ operon to virulence of $E$. tarda. To do this, the same doses of strains (TX01, TX01 $\triangle c a d A$, $\mathrm{TX} 01 \Delta c a d B, \quad \mathrm{TX} 01 \Delta c a d B A, \quad \mathrm{TX} 01 \Delta c a d A C$, and TX01 $\triangle c a d B C$ ) were used to infect tilapia. Viable bacteria from spleen and kidney were determined by plate counting at 24 and $48 \mathrm{~h}$ post-infection. The results show that bacterial amounts in both tissues from TX01 $\Delta c a d A-$, TX01 $\Delta c a d B$ - and TX01 $\Delta c a d B A$-infected tilapias were obviously less than those from TX01-infected tilapias at both infection time points. And the amounts of two complementary strains TX01 $\Delta c a d A C$ and TX01 $\Delta c a d B C$ from infected tilapias were basically equal to those of TX01 (Figure 7). These results imply that the $c a d B A$ operon is involved in the dissemination of E. tarda in the fish tissue.

\section{cadBA expression is up-regulated upon acid stress}

Since $\operatorname{cad} B A$ was closely related to acid tolerance, we wanted to survey the expression of $\operatorname{cadBA}$ under acid pressure. E. tarda in exponential phase were subjected to an acidic medium ( $\mathrm{pH} 5.5$ ) for $1 \mathrm{~h}$, then RNA was extracted and cDNA was obtained. RT-qPCR shows that the expression of $c a d B, c a d A$, and $c a d B A$ was up-regulated 685.5-, 1808.7-, and 1204.1-folds respectively, upon acid stimulation, which was significantly higher than that of the control (Figure 8). The immediate upstream of $c a d B A$ is $c a d C$, so we also surveyed its expression and found that $c a d C$ expression was significantly enhanced (3.2-folds) by acid stimulation (Figure 8). These results indicate that the $\operatorname{cadBA}$ operon is closely involved in acid tolerance of $E$. tarda.

\section{cadBA expression is regulated by $\mathrm{CadC}$}

Since $c a d C$ is located upstream of the $\operatorname{cadBA}$ operon and defined as a transcriptional regulator, and the expression of $c a d C$ was induced by acid stimulation, we speculated that the expression of $c a d B A$ is regulated by CadC. In another study, we obtained a cadC mutant (named TX01 $\Delta c a d C$ ). We first investigated the expression of $c a d B A$ in wild strain TX01 and TX01 $\Delta c a d C$ under normal conditions and acidic conditions. RTqPCR shows that under normal conditions, the expression of $\operatorname{cad} A, \operatorname{cadB}$, and $c a d B A$ in TX01 $\operatorname{cadC}$ was significantly lower than that in TX01, the values were
2.6-, 1.8-, and 1.6-fold, respectively. Under acidic conditions, the expression of $\operatorname{cadA}, \operatorname{cadB}$, and $\operatorname{cadBA}$ in TX01 $\Delta$ cadC was down regulated by 2382.0-, 2848.0-, and 13,777.6-folds respectively, compared to TX01 (Figure 9A). These results support the conclusion that $\mathrm{CadC}$ is an activator of $c a d B A$ transcription, and its regulator role is mainly displayed under acidic conditions.

To detect the regulatory mechanism of CadC on $\operatorname{cadBA}$, the speculative promoter of $\operatorname{cadBA}$, P418, was cloned to a promoter probe plasmid pSC11 resulting in $\mathrm{DH} 5 \alpha / \mathrm{pSC} 418$. Meanwhile, the expression plasmid of $c a d C$ was constructed and named pJR21C. DH5 $\alpha$ / pSC418 cultured on X-gal plate at $\mathrm{pH} 7.0$ and 5.5 in the presence of $5 \mathrm{mM}$ L-lysine shows a weak blue phenotype, indicating that the $\mathrm{P} 418$ promoter has a weak promoter activity. When pJR21C was transformed into $\mathrm{DH} 5 \alpha / \mathrm{pSC} 418$, the blue color of the recombinant strain (DH5 $\alpha / \mathrm{pSC} 418 / \mathrm{pJR} 21 \mathrm{C})$ on the X-gal plate at $\mathrm{pH} 7.0$ remained unchanged in the presence of $5 \mathrm{mM} \mathrm{L}$-lysine, compared to that of the control (DH5 $\alpha / \mathrm{pSC} 418 / \mathrm{pJR} 21)$ (data not shown). However, the blue color of $\mathrm{DH} 5 \alpha$ / pSC418/pJR21C on X-gal plate at pH 5.5 in the presence of $5 \mathrm{mM}$ L-lysine was obviously enhanced, compared to that of the control (Figure 9B). These results suggest that $\mathrm{CadC}$ positively regulates the promoter activity of $c a d B A$ under acidic conditions.

To further analyze the regulation of CadC on $\operatorname{cadBA}$ in vivo, promoter reporter plasmid pJR21-418-lx was introduced into TX01 and TX01 $\triangle c a d C$, and the luminescence induced by promoter P418 was detected. The results show the relative light units of (RLU) of TX01 were $463.5 \mathrm{U}$ and $8513.58 \mathrm{U}$ under normal conditions and acidic induced conditions, respectively, which both are significantly higher than that in TX01 $\triangle$ cadC $(213.7$ $\mathrm{U}$ and $757.95 \mathrm{U}$, respectively), especially under acidic induction conditions (Figure 9C). These results indicate that $\mathrm{CadC}$ positively regulates the transcription of $c a d B A$ in $E$. tarda, especially under acidic conditions.

\section{Discussion}

Pathogenic and commensal bacteria often encounter a lot of strong and mild acidic environments both inside and outside hosts, for example, acid soil and food, the gastrointestinal tract, dental plaque and macrophage phagosome [14]. In general, bacteria are able to maintain a fairly constant internal $\mathrm{pH}$ for survival, which is due to evolving acid tolerance response (ATR) and acid resistance (AR) protection mechanisms [17, 36, 42]. One of the important mechanisms involved in acid resistance is the amino acid decarboxylase system that buffers cytosol and the local extracellular environment to ensure enterobacterial survival at low $\mathrm{pH}$ [43]. Among them, the 
A

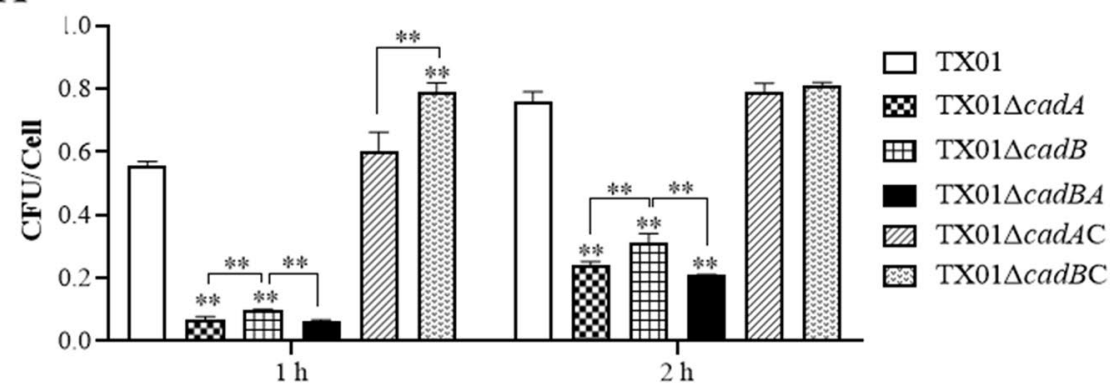

B

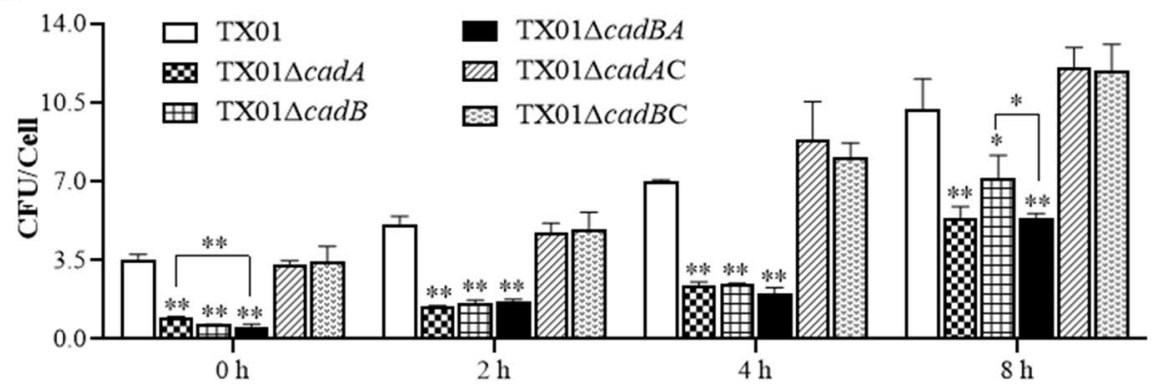

C

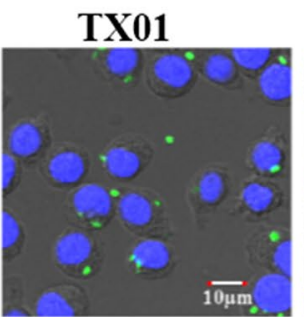

TX01 $\Delta c a d A$
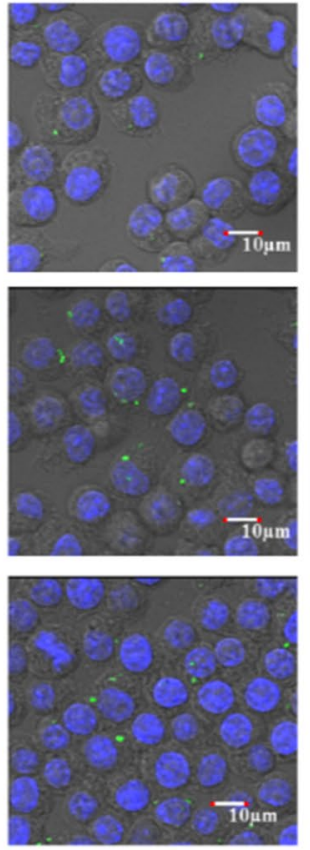

TX01 $\Delta c a d B$
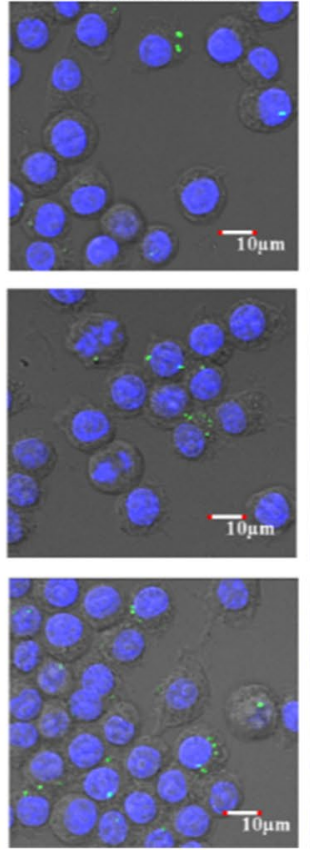

TX01 $\Delta c a d B A$
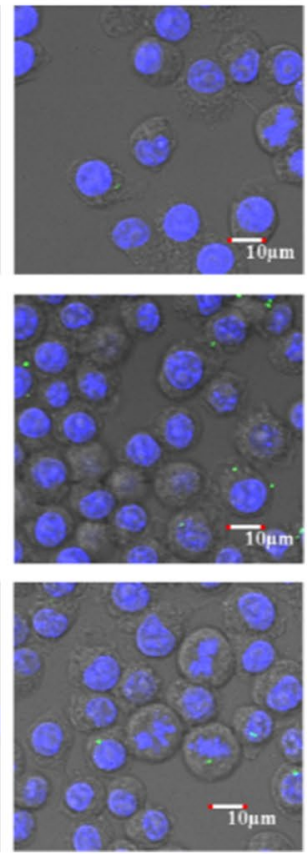

Figure 6 Effects of cadBA mutations on cellular infection and replication. A Invasion of HeLa cells by E. tarda. HeLa cells were infected with the same dose of E. tarda TX01,TX01 $\triangle c a d A, T X 01 \triangle c a d B$, TX01 $\triangle c a d B A$, TX01 $\triangle c a d A C$ and TX01 $\triangle c a d B C$ strains for 1 and $2 \mathrm{~h}$, and washed with PBS. Then, HeLa cells were lysed and the CFU were counted. B Replication of E. tarda in macrophages. The murine macrophage cell line RAW264.7 was infected with E. tarda and mutants above mentioned for $2 \mathrm{~h}$, followed by treatment with gentamicin for $2 \mathrm{~h}$ to kill extracellular bacteria. After being washed with PBS, the cells were incubated for the time intervals indicated. Then, the cells were lysed and the CFU were counted. Data are the means of three independent experiments and presented as means \pm SEM $(N=3)$. $N$, the number of times the experiment was performed. ${ }^{* *}, P<0.01 ; *$, $P<0.05$. C, TX01,TX01 $\triangle c a d A, T X 01 \triangle c a d B$ and TX01 $\triangle$ cadBA containing pGFPuv plasmid were used to infect RAW264.7 cells for 0,2 and 4 h. DNA was stained blue by DAPI, the cells were observed by confocal microscopy. 

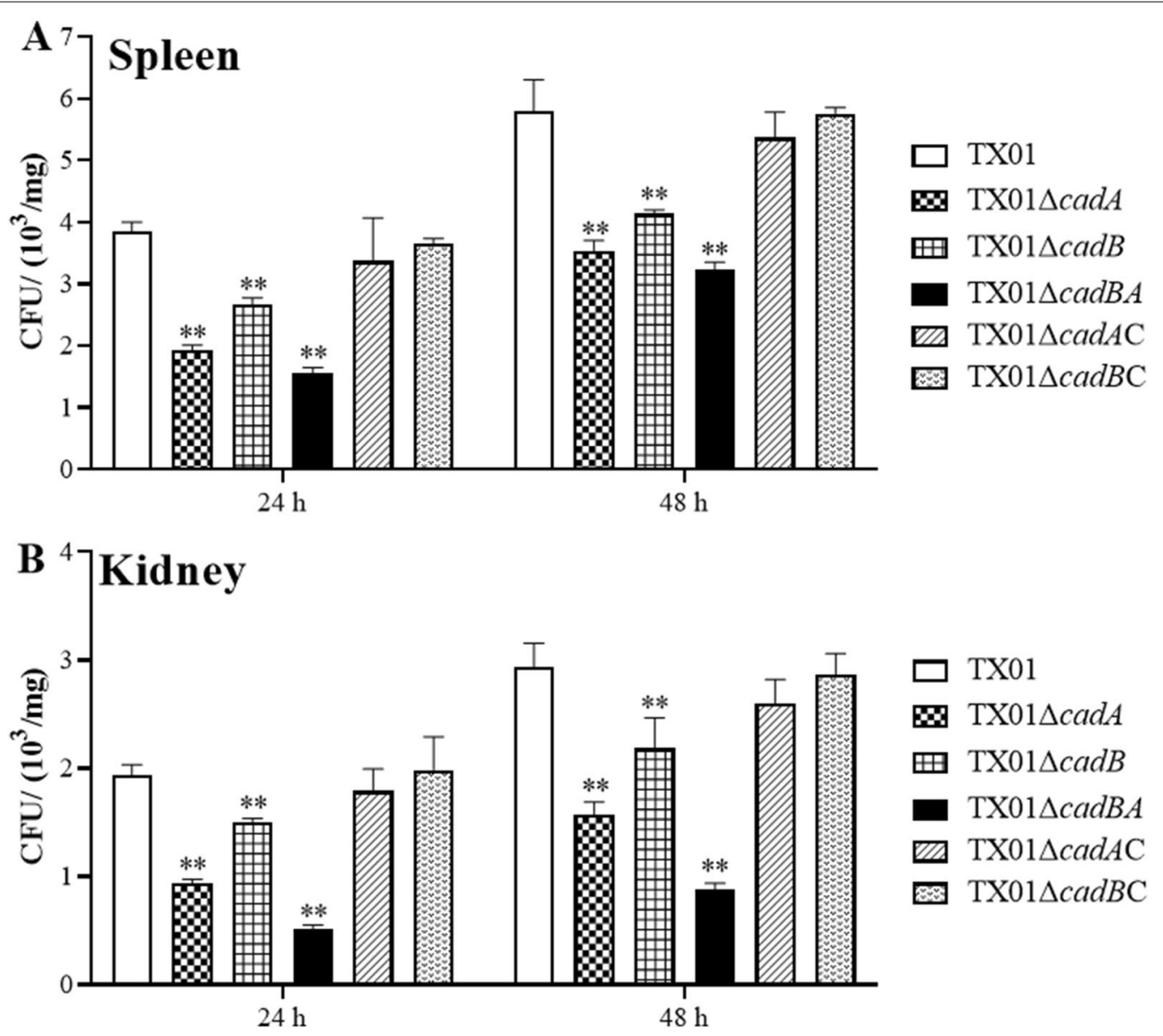

$\square \mathrm{TX} 01$

$\mathbf{D} \mathrm{TX} 01 \Delta c a d A$

田 TX01 $\Delta c a d B$

- TX01 $\triangle c a d B A$

TX $\mathrm{TX} 01 \triangle c a d A C$

$\mathrm{TX} 01 \triangle c a d B C$

Figure 7 Bacterial dissemination in the fish tissues. Tilapia were infected with the same dose of TX01, TX01 $\triangle$ cadA, TX01 $\triangle$ cadB, TX01 $\triangle$ cadBA,

TX01 $\triangle$ cadAC, and TX01 $\triangle c a d B C$. The recoveries of bacteria in spleen $(\mathbf{A})$ and kidney $(\mathbf{B})$ were determined by plate counting at 24 and $48 \mathrm{~h}$

post-infection. Data are presented as means \pm SEM $(N=3)$. $N$, the number of times the experiment was performed. ${ }^{*}, P<0.01$.

lysine-dependent acid resistance (LDAR) system is the mild acid tolerance response system consisting of inducible lysine decarboxylase (CadA) and the lysine/cadaverine antiporter (CadB) [44]. In E. coli, the cadBA operon contains $c a d B$ and $c a d A$ genes, and plays an important role in acid pressure reactions [31]. A similar operon also exists in Salmonella enteric, Vibrio cholera, and Vibrio vulnificus [32, 45, 46]. In E. tarda, cadBA operon also exists. Sequence analysis shows that $\mathrm{CadB}$ is a membrane protein and CadA is an intracellular protein with PLP-binding core domain and the pyridoxal phosphate binding motif. The CadB and CadA of E. tarda share high identities with $\mathrm{CadB}$ and CadA of E. coli, respectively. To date, there are no reports about the LDAR system in $E$. tarda, so we characterized and identified the function of cadBA operon in this study.

As a member of Enterobacteriales, E. tarda can survive and replicate in an acidic environment, but the underlying mechanisms remain unknown. Although some genes or factors, such as Usp13, TAM, HutZ, TrxH, RpoN, and RpoS have been reported to participate in acid tolerance $[37,47-50]$, there is no report about the function of traditional or classical acid resistance in E. tarda. In this study, our results show that compared to wild type TX01, the growth of three mutants TX01 $\Delta c a d A$, TX01 $\Delta c a d B$, and TX01 $\triangle c a d B A$ appeared to be retarded obviously when exposed to an acidic environment $(\mathrm{pH}=5.5$ to 4.5), especially cadA delete mutant TX01 $\Delta c a d A$. Consistently, in V. parahaemolyticus, a mutated strain with a disrupted cadA gene attenuates acid survival [51]. In $V$. vulnificus, cadA mutant accompanying a lack of cadaverine decreases tolerance to low $\mathrm{pH}$ [32]. However, in normal medium (neutral $\mathrm{pH}$ ), the growth rates of TX01 and three mutants are very similar. We observed that the cell densities of TX01 $\Delta c a d A$, TX01 $\triangle c a d B$, and TX01 $\Delta c a d B A$ were similar to that of TX01 at the stationary phase, which may be due to the following two reasons: (i) the $\mathrm{pH}$ of medium was increased; (ii) another acid resistance 


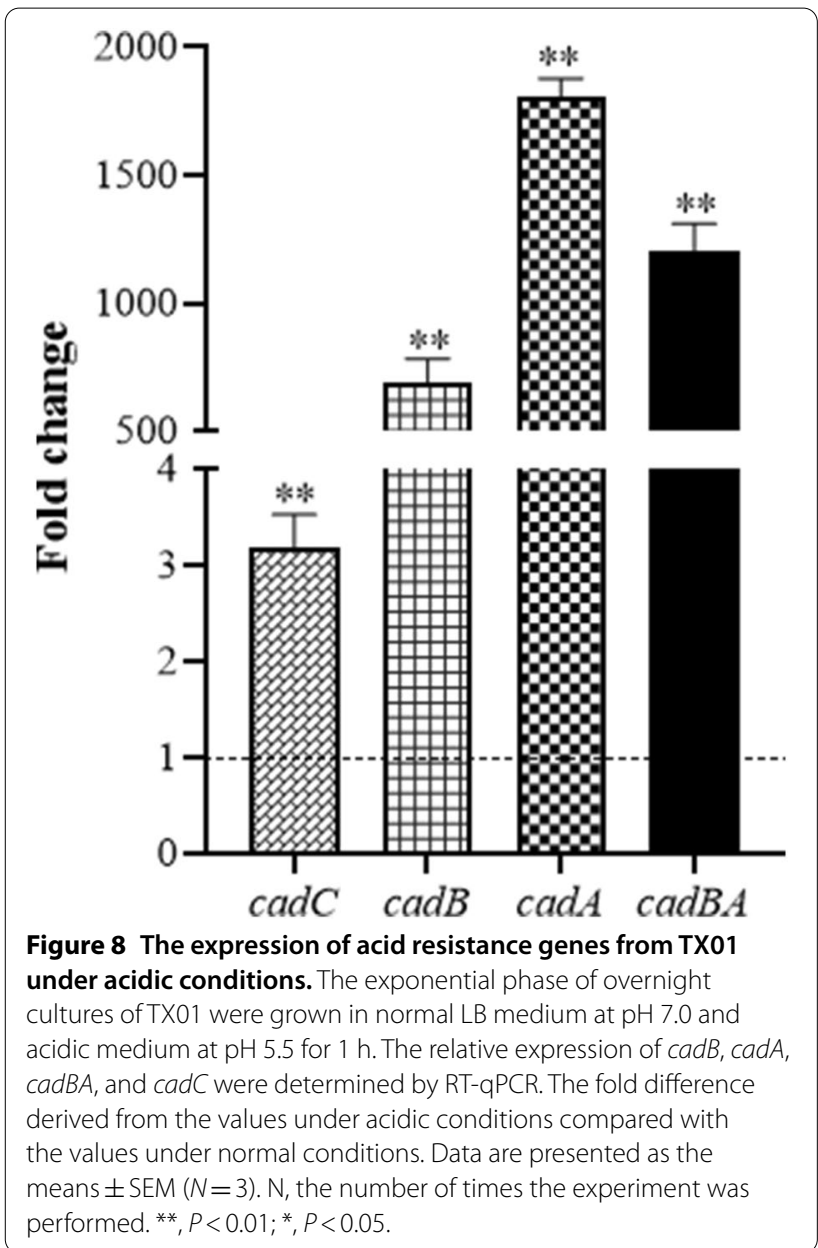

system was activated. These results indicate that $\operatorname{cadBA}$ operon is closely related to acid tolerance of $E$. tarda. In addition, it was reported that microorganisms adapted to mild acid stress may also survive against different types of lethal stress, this kind of multiple adaptive response may be part of a survival strategy [52]. In E. tarda, cadBA operon also plays a role in resistance against iron deficiency and oxidative stress. These findings indicate that $\operatorname{cad} B A$ operon is an important factor of stress resistance in E. tarda.

It has been demonstrated that cadaverine, decarboxylated from lysine, plays a role in acid survival in $E$. coli [53]. The cadaverine was found to be covalently attached to the cell wall peptidoglycan of bacteria. Inhibition of lysine decarboxylase prevented cadaverine accumulation and incorporation into peptidoglycan, resulting in severe inhibition of cell growth under acidic conditions [54-57]. At acidic $\mathrm{pH}$, CadB functions as a cadaverine/lysine antiporter rather than only cadaverine uptake, which catalyses cadaverine excretion and lysine uptake and generates a membrane potential [21]. CadA is acid-inducible lysine decarboxylase, which produces cadaverine and carbon dioxide and generates a $\mathrm{pH}$ gradient through consumption of a cytoplasmic proton, so this proton motive metabolic cycle results in neutralization of acidic conditions [31, 58].

To explore the mechanism that $\operatorname{cad} B A$ contributes to acid tolerance of $E$. $\operatorname{tarda}$, we applied a simple and convenient bromocresol purple-based colorimetric method for fast qualitative detection of lysine decarboxylase activity. Our results show that all mutants exhibited an LDC negative phenotype at the early stages of culture (before $10 \mathrm{~h}$ ), which is inconsistent with the results of quantitative analysis. In quantitative analysis, lysine decarboxylase activities of the three mutants followed the trend of $\mathrm{TX} 01 \Delta c a d B A<\mathrm{TX} 01 \Delta c a d A<\mathrm{TX} 01 \Delta c a d B$. These observations illustrate that $c a d B A$ operon played a critical role in the decarboxylation of lysine of E. tarda, and the LDC activity mainly depended on $\operatorname{cad} A$, which was promoted by $c a d B$. However, at a later stage of culture (30 h), the LDC activity of three mutants was restored to a certain extent, suggesting another minor decarboxylation reaction may be activated when $\operatorname{cad} B A$ operon was inactivated. Unlike E. coli and $V$. cholerae $[59,60]$, the E. tarda genome possesses three genes (ETAE_0284, ETAE_0757, and ETAE_3006) encoding lysine decarboxylase and three genes (ETAE_0283, ETAE_0756, and ETAE_1884) encoding lysine/cadaverine antiporter. RT-qPCR results show that the genes ETAE_3006 and ETAE_1884 were also up-regulated under acidic conditions. However, they do not form the operon, the expression of gene level was lower than that of the $c a d B A$ operon (Additional file 4). We speculated that ETAE_3006 and ETAE_1884 could remedy the deficiency of CadBA to a certain extent at a later stage.

Acid resistance is closely related to biofilm formation. Biofilms are a kind of microbial aggregates embedded in a self-generated matrix of extracellular polymeric substances, by which the microbes can adhere to each other or to the surface of material [61-63]. It has been reported that biofilm formation strengthened bacterial tolerance to acid stress [64]. For example, biofilm formation significantly increased acid tolerance in clinical streptococcal strains, such as Streptococcus gordonii, and S. oralis [65]. Complex biofilms were formed when Pseudomonas aeruginosa was exposed to external acid stress [66]. In this study, we examined the relationship between acid resistance system CadBA and biofilm formation. The results show that whether wild strain TX01 or the three mutants TX01 $\Delta c a d A, \mathrm{TX} 01 \Delta c a d B$, and TX01 $\triangle c a d B A$, their abilities to form biofilms was significantly enhanced when bacteria were exposed to acid stress, which indicates biofilm is needed for bacterial resistance against acid stress. However, the partial 


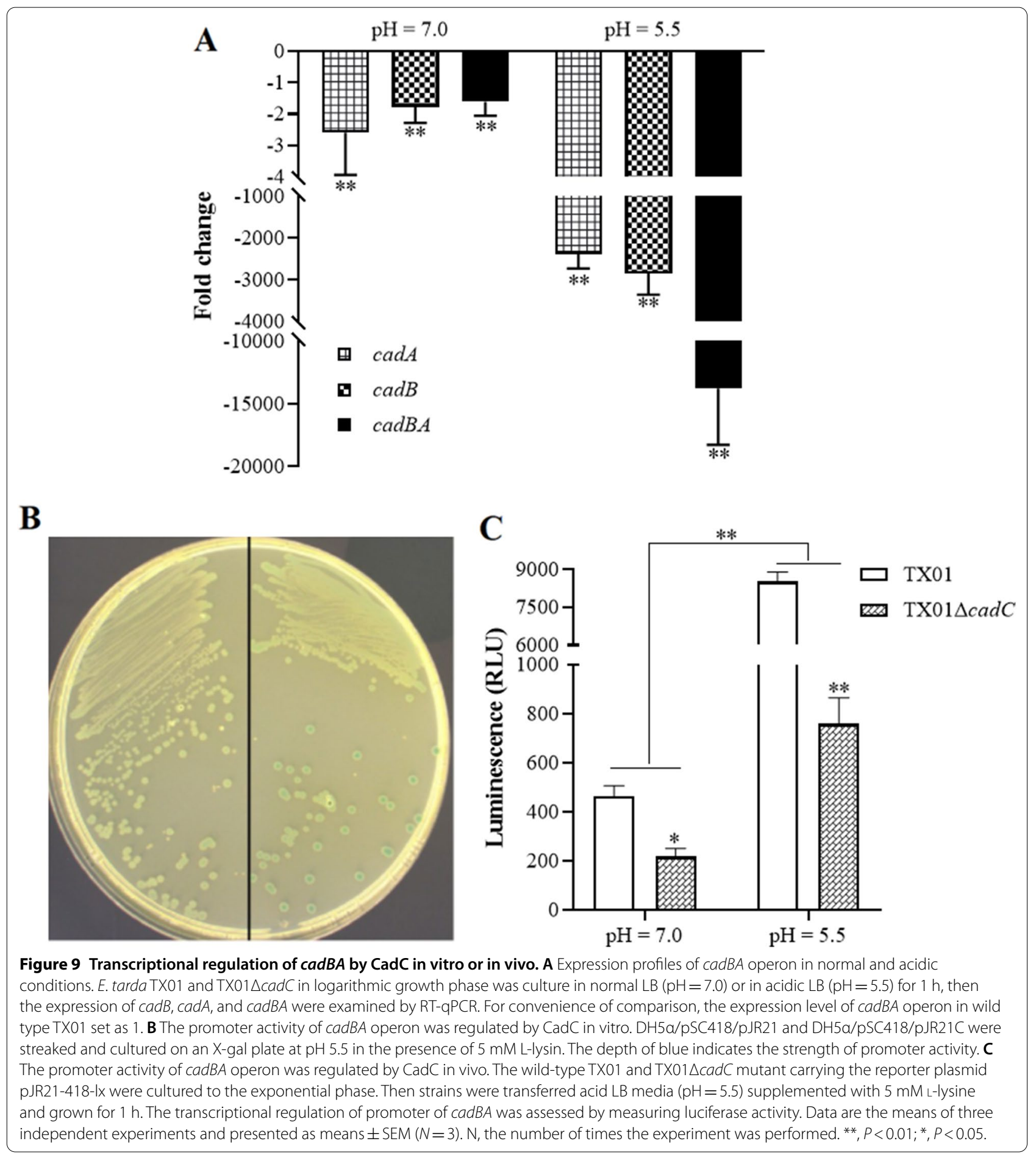

and total inactivation of $c a d B A$ operon significantly increased $E$. tarda's capability of biofilm growth under normal conditions $(\mathrm{pH}=7.0)$ and under acidic conditions $(\mathrm{pH}=5.5)$. Moreover, the biofilm increase by the inactivation of $c a d B A$ operon under acidic conditions was higher than that under normal conditions.
These results illustrate that $\operatorname{cadBA}$ operon negatively participated in the biofilm formation. Different from cadBA, hutZ mutation and usp13 mutation in E. tarda decreased both bacterial resistance against acid stress and biofilm formation [37, 47]. YefM-YoeB operon, a type II TA system, is not related to acid tolerance, but 
its mutation enhanced biofilm formation of E. tarda [34]. In Streptococcus Mutans, urethane dimethacrylate promotes biofilm formation but reduces acid tolerance [67], which is the opposite to the effect of $c a d B A$ in $E$. tarda. This study revealed for the first time, CadBA's involvement in bacterial biofilm formation in an acid resistance system. It was obvious that the relationship between biofilm and acid resistance is complex, and the mechanism is still poorly understood.

The above findings clearly demonstrate that the $c a d B A$ operon was involved in adversity resistance and biofilm formation, which are related to bacterial pathogenicity. It has been reported that $c a d B A$ operon participates in virulence. In $E$. coli, CadA has been proposed to negatively regulate virulence in several enteric pathogens $[68,69]$. When $\operatorname{cadA}$ was introduced into Shigella flexneri, bacterial virulence became attenuated, and enterotoxin activity was greatly inhibited [70]. In contrast, isogenic deletion of cadA in S. pneumoniae TIGR4 led to attenuation of colonization, pneumococcal pneumonia and sepsis in murine models [71]. The toxicity of $\triangle c a d B$ of Aeromonas veronii was 9.5 times less than that of TH0426 in EPC cells [72]. In this study, our results show that the partial or total inactivation of $c a d B A$ operon significantly weakened the ability of $E$. tarda to adhere and invade host non-phagocytes. Complementary strain TX01 $\Delta c a d A C$ recovered the lost virulence of TX01 $\triangle$ cadA. Curiously, complementary strain TX01 $\triangle c a d B C$ exhibited stronger infection ability than the wild type strain at $1 \mathrm{~h}$ post-infection, but was back to the TX01level at $2 \mathrm{~h}$ post-infection. We also noted that TX01 $\triangle$ cadAC partially rescued the lost lysine decarboxylase activity of TX01 $\triangle c a d A$. The reason for the difference exhibited by TX01 $\triangle$ cadAC is worth exploring in the future.

Similarly, the capability of $E$. tarda to survive and replicate in host macrophage cells was significantly declined when the cadBA operon was partially or completely deleted. An in vivo experiment also supported the conclusion that the $\operatorname{cadBA}$ operon contributed to the virulence of $E$. tarda. These findings illustrate that the CadBA acid resistance system plays an important role in virulence of $E$. tarda. Acid stress, as well as iron deficiency and oxidative stress, are important environmental pressures in the host. CadBA promoted the resistance of $E$. tarda to these adversities, and enhanced bacterial motility, thereby contributing to E. tarda's invasion to host cells and the host.

Since $c a d B A$ operon is important for adversity resistance and pathogenicity, its expression is precisely regulated. It is reported that the $c a d B A$ operon is induced at acid conditions coupled with lysine [60, 73]. In this study, we found that the expression of $\operatorname{cadBA}$ operon was remarkably induced by acid stress. For $\operatorname{cad} A$ and
$\operatorname{cadBA}$, their expressions were induced more than 1000 times. This result supports the conclusion that the LDAR system CadBA in E. tarda is important for bacterial acid adaption. It is worth noting that the transcriptional expressions of $c a d B, c a d A$, and $\operatorname{cadBA}$ were different, although $c a d B$ and $c a d A$ are bicistron. Among the abundance of three transcriptions under acid stress, $\operatorname{cad} A$ was the highest, $c a d B A$ the second, and $c a d B$ the lowest. Similar results were observed in Vibrio parahaemolyticus [51]. We speculated that there is another promoter before the ORF of $c a d A$. In addition, $c a d C$, the upstream gene of $\operatorname{cadBA}$, was also induced by acid stress, although its expression was only three folds. Like most $c a d B A$ operons in Enterobacteriaceae, CadC was the regulator of $c a d B A$ operon. To affirm the regulator role of CadC in $E$. tarda, the expression of $c a d B A$ operon was examined in the cadC mutant. RT-qPCR shows that when $c a d C$ was deleted, the expression of the cadBA operon was downregulated, especially under acid conditions, the expression of $c a d B A$ operon was down-regulated by 2382- to 13,778-folds, which also indicates the involvement of cadBA operon in acid tolerance. The assay of detection of promoter activity in vitro and in vivo suggests that $\mathrm{CadC}$ regulated the promoter activity of $c a d B A$ operon. These results illustrate that the expression of $c a d B A$ operon was strictly regulated by CadC, especially under acid conditions.

In conclusion, for the first time we identified and characterized the $\operatorname{cadBA}$ operon in E. tarda, a significant zoonotic pathogen. Our results show that the cadBA operon plays an important role in coping with adverse circumstances, especially acid stress. It is the first time that the $c a d B A$ operon negatively participated in biofilm formation, especially under acid conditions. Our results also demonstrate that $c a d B A$ functions as a new virulence factor that is essential to bacterial infection at the cellular and tissue levels. The expression of $c a d B A$ operon was induced upon acid stress by the regulator CadC. This study provides new insight into the acid resistance mechanism of $E$. tarda.

\footnotetext{
Abbreviations

E. tarda: Edwardsiella tarda; E. anguillarum: Edwardsiella anguillarum; E. ictaluri: Edwardsiella ictaluri; E. hoshinae: Edwardsiella hoshinae; E. piscicida: Edwardsiella piscicida; E. coli: Escherichia coli; V. cholera: Vibrio cholera; S. typhimurium: Salmonella typhimurium; V. vulnificus: Vibrio vulnificus; AR: acid-resistance; ATR: acid tolerance response; PLP: phosphopyridoxal; GDAR: glutamic acid-dependent acid resistance; ADAR: arginine-dependent acid resistance; LDAR: lysine-dependent acid resistance; ODAR: ornithine-dependent acid resistance; LB: Luria-Bertani broth; PCR: Polymerase Chain Reaction; RT-PCR: reverse transcription-PCR; RT-qPCR: quantitative real-time reverse transcription-PCR; ORF: open reading frames; CFU: colony forming unit; Dp: 2,2'-Dipyridyl; LDC: Iysine decarboxylase; OD: optical density; A: absorption; CV: crystal violet; CLSM: confocal laser scanning microscopy; PBS: phosphate-buffered saline; DMEM: Dulbecco's Modified Eagle's medium; MOI: multiplicity of infection; DAPI: 4', 6-Diamidino-2-phenylindole; X-gal:
} 
5-Bromo-4-chloro-3-indolyl-beta-D-galactopyranoside; U: unite; TM: transmembrane domains; i.m.: intramuscular; MS222: tricaine methanesulfonate.

\section{Supplementary Information}

The online version contains supplementary material available at https://doi. org/10.1186/s13567-021-00987-x.

\section{Additional file 1. Sequence alignment of CadA (A) and CadB (B)}

homologues. Gaps used to maximize the alignment are indicated by dots. The complete conserved amino acid residues are shown in dark blue. The amino acid residues with conservative degree higher than $75 \%$ are shown in pink. The black line indicates the $\mathrm{N}$-terminal domain. The green and orange lines indicate the PLP-binding core domain and C-terminal domain, respectively. Red triangles indicate PLP binding sites. Conserve PLP binding motif is yellow boxed. The blue line indicates transmembrane (TM) domains. The GenBank accession numbers of CadA homologues are as follows: Edwardsiella tarda, ACY83602.1; Escherichia coli str. K-12 substr, NP_418555.1; Salamae, VEA01344.1; Aeromonas veronii, QHC07268.1; Vibrio cholerae, WP 188372281.1; Klebsiella pneumoniae, AZH95435.1; Shigella boydii, PHU85906.1. The GenBank accession numbers of CadB homologues are as follows: E. tarda, ACY83601.1; Salmonella enterica, WP_000100010.1; Klebsiella pneumoniae,WP_110924908.1; Escherichia coli, WP_175119720.1; Shigella flexneri, NP_709997.1; Vibrio cholerae, WP_189017881.1; Aeromonas veronii, WP_118881724.1.

Additional file 2. Validation of TX01 mutants by PCR amplification. Lanes 1 and 7 were the 661-bp (deletion of cadA allele) fragments amplified from TX01 $\triangle$ cadA and TX01 $\triangle$ cadBA genomic DNA with primers CadAKOF3/CadAKOR3, respectively. Lane 4 was 1684-bp cadA fragment. Lanes 5 and 8 were the $265 \mathrm{bp}$ (deletion of $c a d B$ allele) fragments amplified from TX01 $\triangle c a d B$ and TX01 $\triangle c a d B A$ genomic DNA with primers CadBKOF3/ CadBKOR3, respectively. Lane 2 was 901-bp cadB fragment. Lanes 3, 6 and 9 were $16 \mathrm{~S}$ rRNA gene fragments amplified from three mutants with universal primers 27F/1492R. M is DS 2000 marker.

Additional file 3 . The swimming ability of complementary strains TX01 $\triangle c a d A C$ and TX01 $\triangle c a d B C$ in the acid swimming plate. TX01, $T X 01 \triangle c a d A C$, and TX01 $\triangle$ cadBC were cultured in LB medium to an $\mathrm{OD}_{600}$ of 0.5 , then aliquots of cell suspensions $(1 \mu \mathrm{L})$ were inoculated into the center of swimming plates including $0.3 \%$ (W/N) agar with $\mathrm{pH}=5.5$ at $30^{\circ} \mathrm{C}$ for $18 \mathrm{~h}(\mathbf{A})$. The diameter of the swimming zone from the swimming plate at $\mathrm{pH}=5.5(\mathbf{B})$. The data are presented as the means \pm SEM $(N=3)$. $\mathrm{N}$, the number of times the experiment was performed. ${ }^{* *}, P<0.01$.

\section{Additional file 4. The expression of acid resistance genes in}

Edwardsiella tarda under acidic conditions. The exponential phase of overnight cultures of TX01 were grown in normal LB medium at $\mathrm{pH} 7.0$ and acidic medium at $\mathrm{pH} 5.5$ for $1 \mathrm{~h}$. The relative expression of ETAE_3006 and ETAE_1884 were determined by RT-qPCR. The fold difference derived from the values under acidic conditions compared with the values under normal conditions. Data are presented as the means \pm SEM $(N=3)$. N, the number of times the experiment was performed. ${ }^{*}, P<0.01$.

\section{Acknowledgements}

The authors would like to thank professor Jianqiang Lin at Shandong University for his kind provision of plamids; Associate professor Hao Long at Hainan University for providing reagents; Professor Huiqin Huang at Institute of Tropical Bioscience and Biotechnology for technical assistances.

\section{Authors' contributions}

CMD performed the experiments, analyzed the data, and wrote the paper. $\mathrm{XPH}$ participated in the infection experiments, HJG participated in the expression analysis. DMW and $\mathrm{YHH}$ designed the experiment. $\mathrm{YHH}$ wrote the paper. All authors read and approved the final manuscript.

\section{Funding}

This work was supported by the Hainan Provincial Natural Science Foundation of China (2019CXTD413), the Central Public-interest Scientific Institution Basal Research Fund for Chinese Academy of Tropical Agricultural Sciences
(1630052019003, 1630052021020), National Natural Science Foundation of China $(41476138,21777060)$, the Basic Scientific Research Project of the Higher Education Institutions of Heilongjiang Province (2020-KYYWF-0234), Joint Guidance Project of Natural Science Foundation of Heilongjiang Province (LH2019H058).

\section{Availability of data and materials}

All data generated or analyzed during this study are included in this published article.

\section{Declarations}

\section{Ethics approval and consent to participate}

The study was approved by the ethics committee of Institute of Tropical Bioscience and Biotechnology, Chinese Academy of Tropical Agricultural Sciences (ID Number: ITBB202001). Efforts were taken to ensure that all research animals received good care and humane treatment.

\section{Competing interests}

The authors have no conflicting commercial or financial interest in publishing this paper

\section{Author details}

${ }^{1}$ College of Basic Medicine, Jiamusi University, 154007 Jiamusi, China. ${ }^{2}$ Institute of Tropical Bioscience and Biotechnology, Hainan Academy of Tropical Agricultural Resource, CATAS, 571101 Haikou, China. ${ }^{3}$ Laboratory for Marine Biology and Biotechnology, Pilot National Laboratory for Marine Science and Technology (Qingdao), 266071 Qingdao, China. ${ }^{4}$ College of Life Science, Jiamusi University, 154007 Jiamusi, China. ${ }^{5}$ Heilongjiang Provincial Key Laboratory of New Drug Development and Evaluation of the Efficacy of Toxicology, 154007 Jiamusi, China. ${ }^{6}$ Hainan Provincial Key Laboratory for Functional Components Research and Utilization of Marine Bio-Resources, $571101 \mathrm{Hai}-$ kou, China.

Received: 27 May 2021 Accepted: 27 July 2021

Published online: 14 September 2021

\section{References}

1. Ewing WH, Mcwhorter AC, Escobar MR, Lubin AH (1965) Edwardsiella, a new genus of Enterobacteriaceae based on a new species, E. tarda. Int $J$ Syst Evol Microbiol 15:33-38

2. Abayneh T, Colquhoun DJ, Sørum H (2013) Edwardsiella piscicida sp. nov., a novel species pathogenic to fish. J Appl Microbiol 114:644-654

3. Leung KY, Wang Q, Yang Z, Siame BA (2019) Edwardsiella piscicida: a versatile emerging pathogen of fish. Virulence 10:555-567

4. Griffin MJ, Quiniou SM, Cody T, Tabuchi M, Ware C, Cipriano RC, Mauel MJ, Soto E (2013) Comparative analysis of Edwardsiella isolates from fish in the eastern United States identifies two distinct genetic taxa amongst organisms phenotypically classified as E. tarda. Vet Microbiol 165:358-372

5. Wang C, Dong XS, Yang YY, Xu GJ, Wu MM, Yan FJ, Zhang LG, An L, Fu PS, Wang XR, Su YB, Meng QL (2021) Metabolites in the TCA cycle promote resistance to chloramphenicol of Edwardsiella tarda. J Proteome Res 20:972-981

6. Han HH, Li T, Wang ZL, Teng D, Mao RY, Hao Y, Yang N, Wang XM, Wang JH (2020) Improved stability and activity of a marine peptide-N6NH2 against Edwardsiella tarda and its preliminary application in fish. Mar Drugs 18:650

7. Sayed M, Ozdemir O, Essa M, Olivier A, Karsi A, Lawrence ML, Abdelhamed $H$ (2021) Virulence and live vaccine potential of Edwardsiella piscicida phoP and phoQ mutants in catfish against edwardsiellosis. J Fish Dis 44:1463-1474

8. Buján N, Toranzo AE, Magariños B (2018) Edwardsiella piscicida: a significant bacterial pathogen of cultured fish. Dis Aquat Organ 131:59-71

9. Bockemühl J, Pan-Urai R, Burkhardt F (1971) Edwardsiella tarda associated with human disease. Pathol Microbiol (Basel) 37:393-401

10. Lee W, Oh JY, Kim EA, Kang N, Kim KN, Ahn G, Jeon YJ (2016) A prebiotic role of Ecklonia cava improves the mortality of Edwardsiella tarda-infected 
zebrafish models via regulating the growth of lactic acid bacteria and pathogen bacteria. Fish Shellfish Immunol 54:620-628

11. Gao YL, Tang XQ, Sheng XZ, Xing J, Zhan WB (2015) Immune responses of flounder Paralichthys olivaceus vaccinated by immersion of formalininactivated Edwardsiella tarda following hyperosmotic treatment. Dis Aquat Organ 116:111-120

12. Wang IK, Kuo HL, Chen YM, Lin CL, Chang HY, Chuang FR, Lee MH (2005) Extraintestinal manifestations of Edwardsiella tarda infection. Int J Clin Pract 59:917-921

13. Nelson JJ, Nelson CA, Carter JE (2009) Extraintestinal manifestations of Edwardsiella tarda infection: a 10-year retrospective review. J La State Med Soc 161:103-106

14. Lund P, Tramonti A, De Biase D (2014) Coping with low pH: molecular strategies in neutralophilic bacteria. FEMS Microbiol Rev 38:1091-1125

15. Park YK, Bearson B, Bang SH, Bang IS, Foster JW (1996) Internal pH crisis, lysine decarboxylase and the acid tolerance response of Salmonella typhimurium. Mol Microbiol 20:605-611

16. Brameyer S, Hoyer E, Bibinger S, Burdack K, Lassak J, Jung K (2020) Molecular design of a signaling system influences noise in protein abundance under acid stress in different $\mathrm{Y}$-Proteobacteria. J Bacteriol. https://doi.org/ 10.1128/JB.00121-20

17. Xu Y, Zhao Z, Tong W, Ding Y, Liu B, Shi Y, Wang J, Sun S, Liu M, Wang Y, Q Q, Xian M, Zhao G (2020) An acid-tolerance response system protecting exponentially growing Escherichia coli. Nat Commun 11:1496

18. Krammer EM, Prevost M (2019) Function and regulation of acid resistance antiporters. J Membr Biol 252:465-481

19. De Biase D, Tramonti A, Bossa F, Visca P (1999) The response to stationaryphase stress conditions in Escherichia coli: role and regulation of the glutamic acid decarboxylase system. Mol Microbiol 32:1198-1211

20. Iyer R, Williams C, Miller C (2003) Arginine-agmatine antiporter in extreme acid resistance in Escherichia coli. J Bacteriol 185:6556-6561

21. Soksawatmaekhin W, Kuraishi A, Sakata K, Kashiwagi K, Igarashi K (2004) Excretion and uptake of cadaverine by $\mathrm{CadB}$ and its physiological functions in Escherichia coli. Mol Microbiol 51:1401-1412

22. Kashiwagi K, Shibuya S, Tomitori H, Kuraishi A, Igarashi K (1997) Excretion and uptake of putrescine by the PotE protein in Escherichia coli. J Biol Chem 272:6318-6323

23. Kanjee U, Gutsche I, Alexopoulos E, Zhao B, Bakkouri El, M, Thibault G, Liu K, Ramachandran S, Snider J, Pai EF, Houry WA, (2011) Linkage between the bacterial acid stress and stringent responses: the structure of the inducible lysine decarboxylase. Embo J 30:931-944

24. Diez-Gonzalez F, Karaibrahimoglu Y (2004) Comparison of the glutamatearginine- and lysine-dependent acid resistance systems in Escherichia coli O157:H7. J Appl Microbiol 96:1237-1244

25. Auger EA, Redding KE, Plumb T, Childs LC, Meng SY, Bennett GN (1989) Construction of lac fusions to the inducible arginine- and lysine decarboxylase genes of Escherichia coli K12. Mol Microbiol 3:609-620

26. Sabo DL, Boeker EA, Byers B, Waron H, Fischer EH (1974) Purification and physical properties of inducible Escherichia coli lysine decarboxylase. Biochemistry 13:662-670

27. Dell CL, Neely MN, Olson ER (1994) Altered pH and lysine signalling mutants of cadC, a gene encoding a membrane-bound transcriptional activator of the Escherichia coli cadBA operon. Mol Microbiol 14:7-16

28. Miller VL, Taylor RK, Mekalanos JJ (1987) Cholera toxin transcriptional activator toxR is a transmembrane DNA binding protein. Cell 48:271-279

29. Rauschmeier M, Schüppel V, Tetsch L, Jung K (2014) New insights into the interplay between the lysine transporter LysP and the pH sensor CadC in Escherichia coli. J Mol Biol 426:215-229

30. Schlundt A, Buchner S, Janowski R, Heydenreich T, Heermann R, Lassak J, Geerlof A, Stehle R, Niessing D, Jung K, Sattler M (2017) Structure-function analysis of the DNA-binding domain of a transmembrane transcriptional activator. Sci Rep 7:1051

31. Meng SY, Bennett GN (1992) Nucleotide sequence of the Escherichia coli cad operon: a system for neutralization of low extracellular pH. J Bacteriol 174:2659-2669

32. Rhee JE, Kim KS, Choi SH (2005) CadC activates pH-dependent expression of the Vibrio vulnificus cadBA operon at a distance through direct binding to an upstream region. J Bacteriol 187:7870-7875

33. Zhang M, Jiao XD, Hu YH, Sun L (2009) Attenuation of Edwardsiella tarda virulence by small peptides that interfere with LuxS/autoinducer type 2 quorum sensing. Appl Environ Microbiol 75:3882-3890
34. Ma DM, Gu HJ, Shi YJ, Huang HQ, Sun DM, Hu YH (2021) Edwardsiella piscicida YefM-YoeB: a type II Toxin-Antitoxin system that is related to antibiotic resistance, biofilm formation, serum survival, and host infection. Front Microbiol 12:646299

35. Hu YH, Sun L (2016) The global regulatory effect of Edwardsiella tarda Fur on iron acquisition, stress resistance, and host infection: a proteomicsbased interpretation. J Proteomics 140:100-110

36. Ante VM, Bina XR, Bina JE (2015) The LysR-type regulator LeuO regulates the acid tolerance response in Vibrio cholerae. Microbiology 161:2434-2443

37. Shi YJ, Fang QJ, Huang HQ, Gong CG, Hu YH (2019) HutZ is required for biofilm formation and contributes to the pathogenicity of Edwardsiella piscicida. Vet Res 50:76

38. Du HH, Zhou HZ, Tang P, Huang HQ, Liu M, Hu YH (2018) Global discovery of small RNAs in the fish pathogen Edwardsiella piscicida: key regulator of adversity and pathogenicity. Vet Res 49:120

39. Xie JH, Zhao QY, Huang HQ, Fang ZG, Hu YH (2021) Edwardsiella piscicida HigB: a type Il toxin that is essential to oxidative resistance, biofilm formation, serum survival, intracellular propagation, and host infection. J Aquaculture 535:736382

40. Wang D, Gong CG, Gu HJ, Huang HQ, Xian JN, Hu YH (2021) Bicistronic operon YhaO-YhaM contributes to antibiotic resistance and virulence of pathogen Edwardsiella piscicida. Aquaculture 541:736849

41. Wang F, Cheng S, Sun K, Sun L (2008) Molecular analysis of the fur (ferric uptake regulator) gene of a pathogenic Edwardsiella tarda strain. J Microbiol 46:350-355

42. Perez JC, Groisman EA (2007) Acid pH activation of the PmrA/PmrB two-component regulatory system of Salmonella enterica. Mol Microbiol 63:283-293

43. Jessop M, Liesche C, Felix J, Desfosses A, Baulard M, Adam V, Fraudeau A, Huard K, Effantin G, Kleman JP, Bacia-Verloop M, Bourgeois D, Gutsche I (2021) Supramolecular assembly of the Escherichia coli Ldcl upon acid stress. Proc Natl Acad Sci U S A 118:e2014383118

44. Merrell DS, Camilli A (2000) Regulation of vibrio cholerae genes required for acid tolerance by a member of the "ToxR-like" family of transcriptional regulators. J Bacteriol 182:5342-5350

45. Lee YH, Kim BH, Kim JH, Yoon WS, Bang SH, Park YK (2007) CadC has a global translational effect during acid adaptation in Salmonella enterica serovar Typhimurium. J Bacteriol 189:2417-2425

46. Ante VM, Bina XR, Bina JE (2015) The LysR-type regulator LeuO regulates the acid tolerance response in Vibrio cholerae. Microbiology (Reading) 161:2434-2443

47. Fang QJ, Han YX, Shi YJ, Huang HQ, Fang ZG, Hu YH (2019) Universal stress proteins contribute Edwardsiella piscicida adversity resistance and pathogenicity and promote blocking host immune response. Fish Shellfish Immunol 95:248-258

48. Li MF, Jia BB, Sun YY, Sun L (2020) The translocation and assembly module (TAM) of Edwardsiella tarda is essential for stress resistance and host infection. Front Microbiol 11:1743

49. Wang BY, Huang HQ, Li S, Tang P, Dai HF, Xian JA, Sun DM, Hu YH (2019) Thioredoxin $\mathrm{H}(\mathrm{Tr} x \mathrm{H})$ contributes to adversity adaptation and pathogenicity of Edwardsiella piscicida. Vet Res 50:26

50. Liu E, Ye J, Song SS, Wang K, Zhang YX, Zhang HZ (2014) Impact of codeficiency of RpoN and RpoS on stress tolerance, virulence and gene regulation in Edwardsiella tarda. J Basic Microbiol 54:678-687

51. Tanaka Y, Kimura B, Takahashi H, Watanabe T, Obata H, Kai A, Morozumi S, Fujii T (2008) Lysine decarboxylase of Vibrio parahaemolyticus: kinetics of transcription and role in acid resistance. J Appl Microbiol 104:1283-1293

52. Xu H, Lee HY, Ahn J (2008) Cross-protective effect of acid-adapted Salmonella enterica on resistance to lethal acid and cold stress conditions. Lett Appl Microbiol 47:290-297

53. Samartzidou H, Mehrazin M, Xu Z, Benedik MJ, Delcour AH (2003) Cadaverine inhibition of porin plays a role in cell survival at acidic $\mathrm{pH}$. J Bacteriol 185:13-19

54. Kojima S, Kaneko J, Abe N, Takatsuka Y, Kamio Y (2011) Cadaverine covalently linked to the peptidoglycan serves as the correct constituent for the anchoring mechanism between the outer membrane and peptidoglycan in Selenomonas ruminantium. J Bacteriol 193:2347-2350

55. Kamio Y, Pösö H, Terawaki Y, Paulin L (1986) Cadaverine covalently linked to a peptidoglycan is an essential constituent of the peptidoglycan 
necessary for the normal growth in Selenomonas ruminantium. J Biol Chem 261:6585-6589

56. Hirao T, Sato M, Shirahata A, Kamio Y (2000) Covalent linkage of polyamines to peptidoglycan in Anaerovibrio lipolytica. J Bacteriol 182:1154-1157

57. Hamana K, Saito T, Okada M, Sakamoto A, Hosoya R (2002) Covalently linked polyamines in the cell wall peptidoglycan of Selenomonas, Anaeromusa, Dendrosporobacter, Acidaminococcus and Anaerovibrio belonging to the Sporomusa subbranch. J Gen Appl Microbiol 48:177-180

58. Han LF, Yuan JJ, Ao XL, Lin SJ, Han X, Ye HH (2018) Biochemical characterization and phylogenetic analysis of the virulence factor lysine decarboxylase from Vibrio vulnificus. Front Microbiol 9:3082

59. Kikuchi Y, Kojima H, Tanaka T, Takatsuka Y, Kamio Y (1997) Characterization of a second lysine decarboxylase isolated from Escherichia coli. J Bacteriol 179:4486-4492

60. Merrell DS, Camilli A (1999) The cadA gene of Vibrio cholerae is induced during infection and plays a role in acid tolerance. Mol Microbiol 34:836-849

61. Wang D, Xu AM, Elmerich C, Ma LZ (2017) Biofilm formation enables free-living nitrogen-fixing rhizobacteria to fix nitrogen under aerobic conditions. ISME J 11:1602-1613

62. Li Q, Sand W (2017) Mechanical and chemical studies on EPS from Sulfobacillus thermosulfidooxidans: from planktonic to biofilm cells. Colloids Surf B Biointerfaces 153:34-40

63. Hu WB, Feng SS, Tong YJ, Zhang HL, Yang HL (2020) Adaptive defensive mechanism of bioleaching microorganisms under extremely environmental acid stress: advances and perspectives. Biotechnol Adv 42:107580

64. Edwards SJ, Kjellerup BV (2013) Applications of biofilms in bioremediation and biotransformation of persistent organic pollutants, pharmaceuticals/ personal care products, and heavy metals. Appl Microbiol Biotechnol 97:9909-9921

65. Boisen G, Davies JR, Neilands J (2021) Acid tolerance in early colonizers of oral biofilms. BMC Microbiol 21:45
66. Williams P, Cámara M (2009) Quorum sensing and environmental adaptation in Pseudomonas aeruginosa: a tale of regulatory networks and multifunctional signal molecules. Curr Opin Microbiol 12:182-191

67. Kim K, Kim JN, Lim BS, Ahn SJ (2021) Urethane dimethacrylate influences the cariogenic properties of Streptococcus mutans. Materials (Basel) 14:1015

68. Vazquez-Juarez RC, Kuriakose JA, Rasko DA, Ritchie JM, Kendall MM, Slater TM, Sinha M, Luxon BA, Popov VL, Waldor MK, Sperandio V, Torres AG (2008) CadA negatively regulates Escherichia coli O157:H7 adherence and intestinal colonization. Infect Immun 76:5072-5081

69. Jores J, Torres AG, Wagner S, Tutt CB, Kaper JB, Wieler LH (2006) Identification and characterization of "pathoadaptive mutations" of the cadBA operon in several intestinal Escherichia coli. Int J Med Microbiol 296:547-552

70. Maurelli AT, Fernández RE, Bloch CA, Rode CK, Fasano A (1998) "Black holes" and bacterial pathogenicity: a large genomic deletion that enhances the virulence of Shigella spp. and enteroinvasive Escherichia coli. Proc Natl Acad Sci U S A 95:3943-3948

71. Nakamya MF, Ayoola MB, Park S, Shack LA, Swiatlo E, Nanduri B (2018) The role of cadaverine synthesis on pneumococcal capsule and protein expression. Med Sci (Basel) 6:8

72. Tao LT, Kang YH, Zhang L, Shi QM, Li Y, Wu TL, Qian AD, Sun WW, Shan XF (2020) Cadaverine reverse transporter (CadB protein) contributes to the virulence of Aeromonas veronii TH0426. Int Microbiol 23:489-499

73. Kuper C, Jung K (2005) CadC-mediated activation of the cadBA promoter in Escherichia coli. J Mol Microbiol Biotechnol 10:26-39

\section{Publisher's Note}

Springer Nature remains neutral with regard to jurisdictional claims in published maps and institutional affiliations.
Ready to submit your research? Choose BMC and benefit from:

- fast, convenient online submission

- thorough peer review by experienced researchers in your field

- rapid publication on acceptance

- support for research data, including large and complex data types

- gold Open Access which fosters wider collaboration and increased citations

- maximum visibility for your research: over 100M website views per year

At BMC, research is always in progress.

Learn more biomedcentral.com/submissions 